\title{
Traffic Congestion: An Experimental Study of the Downs-Thomson Paradox
}

\author{
Emmanuel Dechenaux \\ Kent State University, Kent, OH 44242 \\ edechena@kent.edu \\ Shakun D. Mago \\ University of Richmond, Richmond, VA 23173 \\ sdatta@richmond.edu \\ Laura Razzolini \\ Virginia Commonwealth University, Richmond, VA 23284 \\ lrazzolini@vcu.edu
}

February 2, 2013

This study considers a model of road congestion with average cost pricing. Subjects must choose between two routes - Road and Metro. Travel cost on the road is increasing in the number of commuters who choose this route, while travel cost on the metro is decreasing in the number of its users. We examine how changes to road capacity, number of commuters, and metro pricing scheme influence the commuters' route-choice behavior. According to the Downs-Thomson paradox, improved road capacity increases travel times along both routes because it attracts more users to the road and away from the metro, thereby worsening both services. A change in route design generates two Nash equilibria; and the resulting coordination problem is amplified even further when the number of commuters is large. We find that, similar to other binary choice experiments with congestion effects, aggregate traffic flows are close to the equilibrium levels, but systematic individual differences persist over time.

Keywords: Congestion; Laboratory experiments; Downs-Thomson Paradox; Coordination JEL Codes: C91; C92; D83; R40; R41

Corresponding author: Shakun D. Mago; Address: Robins School of Business, 1 Gateway Road, Richmond, VA 23173, USA; Phone: 804-287-6631; Fax: 804-289-8878

This research is funded by the National Science Foundation (Grant 0527534). We thank Tim Cason, Oleg Korenok, the editor Jacob Goeree, and the seminar participants at the University of Siena, Italy, the International Meeting of the Economic Science Association, and the European Meeting of the Economic Science Association for helpful comments. 


\section{Introduction}

There is common agreement that traffic congestion is one of the biggest problems in every day modern life. Traffic congestion creates a number of costs. There is a time cost, such as increased average travel time and unexpected delays; a physical cost, such as the cost of fuel and the depreciation of vehicles; and further environmental and social costs associated with noise and air pollution. The Texas Transportation Institute estimated congestion costs to be over \$101 billion in 75 metropolitan areas during 2010 because of time delays (4.8 billion hours) and fuel consumed (1.9 billion extra gallons). ${ }^{1}$

The standard remedy to traffic congestion is to 'build our way out' (Arnott and Small, 1994, pg. 446). This may literally mean to build more roads or enlarge existing ones. It may also mean to build new capacity in the form of alternative forms of transportation or change the price of these alternatives modes of transport. These improvements, however, can induce behavioral changes which, although beneficial to the specific commuter, may have detrimental consequences for the efficiency of the system in particular, and for society as a whole.

In this study we consider a model of road congestion in a situation where to reach their final destination, commuters must choose between two transportation modes: a congestible Road or an alternative public transit option such as the Metro. ${ }^{2}$ The travel cost on the road is increasing in the number of commuters who choose it, while the travel cost on the metro is decreasing in the number of its users. This last assumption incorporates the response of the service operator to a reduction in the metro traffic. More explicitly, while an individual commuter would prefer to commute in an empty wagon as opposed to a full one, the operator will face higher costs as the number of metro users decreases. These costs may be offset by lowering the frequency of operation or by increasing fares, to the detriment of the metro user.

In this setup, we examine how changes to road capacity, to the number of commuters and to the metro pricing scheme influence the commuters' route-choice behavior. In

\footnotetext{
${ }^{1}$ The data are from the 2011 Urban Mobility Report, Texas Transportation Institute. This cost excludes the environmental cost of pollutants produced by the extra fuel and the resulting health cost. Further, "in round numbers, the evidence suggests that each additional ten minutes in daily commuting time cuts involvement in community affairs by ten percent” (Putnam, 2000, pg.213).

${ }^{2}$ To be consistent with the literature, hereafter we will refer to transportation modes as 'route' choices.
} 
particular, by changing the road capacity, we verify the realization of the DownsThomson paradox. This paradox asserts that expanding the road capacity, as a remedy to traffic congestion, is not only ineffective but often counterproductive. As the road service improves and the commuters switch from the metro to the road, the metro may run less frequently and the worsened service may further induce additional commuters to switch, until the benefit of improved road capacity dissipates completely. Thus, an improvement in road capacity results in the system settling into an equilibrium far worse than before, as the travel time increases for commuters on both the road and the metro.

"Traffic expands to meet the available road space" was posited as the "Iron Law of Congestion” by Downs (1962) and Thomson (1977). Although the paradox is well accepted in the theoretical literature, there is little empirical evidence to support it. In perhaps the only empirical work, Mogridge (1990) documents the case study of London in the book "Travel in towns: jam yesterday, jam today and jam tomorrow?" He found that congestion in central London can be attributed to the increase in road capacity over time and the resulting decline in mass transit traffic. ${ }^{3}$ Horowitz (1984), however, notes that empirical investigations of route choice behavior and the validity of the equilibrium assumptions in real networks cannot be resolved using field data. The variety and the complexity of ways in which current travel decisions may depend on past network performance, and the complete lack of empirical information about the form of this dependence, renders the usefulness of 'natural experiments' in real networks doubtful. Furthermore, the documented difference between the measured traffic volumes and those computed with equilibrium models (as large as 30-50\%) could be a result of model misspecification rather than equilibrium failure. Laboratory experiments, in contrast, provide a controlled setting to examine the behavioral relevance of equilibrium prediction, and to "bench-test" competing public policy options.

The objective of our paper is to provide experimental evidence for the DownsThomson paradox. This is a well-known result in the transportation literature, and Arnott and Small attribute the genesis of this paradox to the fact that "new capacity generates more than its own demand” (1994, pg. 450). More explicitly, each metro user creates

\footnotetext{
${ }^{3}$ This support for the paradox played a crucial role in the implementation of an urban pricing scheme in London in the subsequent years.
} 
external benefits for others, whereas each road user imposes an external cost on the other commuters. Furthermore, the negative externality is continuous, as the travel cost increases at a constant rate with the number of road users. On the other hand, in the case of the metro, the travel cost increases sharply and in a discontinuous fashion as the number of metro users decreases below a certain level. Therefore, the positive externality generated by the metro users comes in discrete steps, similar to a step-level public goods game. The equilibrium implies more road users than in the Pareto efficient outcome; and as the number of road users increases, the benefits inherent in the metro service are thwarted while the increased costs are shared by all commuters. Thus, the DownsThomson paradox poses an important empirical question in the congestion literature. But even abstracting from its application to traffic, it is of interest to behavioral game theorists. The paradox is an example of a theoretical result that stems from equilibrium behavior, but its behavioral plausibility remains unclear.

We seek to examine the extent to which subjects internalize the social cost their decisions impose on others, in a full feedback neutral environment. Our results provide insight into the unintended and undesired behavioral changes induced by improvements to a network, which can be of practical importance to providers and managers of any network - information, material or personnel based.

After establishing the Downs-Thomson Paradox, we explore two additional facets: the impact of alternative pricing policies for the metro service and the impact of population size. Most traffic studies assume constant cost along the uncongested route (metro). We compare the constant cost structure with an average cost structure to examine the extent to which the latter is responsible for the Downs-Thomson paradox. Our assumption of average cost pricing structure for the metro is a close, and perhaps more realistic, approximation of the "increasing returns from added flow," traditionally featured in the Downs-Thomson paradox. We also vary the commuter population size to study whether, and to what extent, coordination problems become more pronounced in case of a larger population. To the best of our knowledge, this is the first study that accounts for the impact of population size in the context of entry games.

We report the results from a series of 14 experimental sessions. We confirm that increased road capacity diverts commuters to the congestible road, and this worsens the 
metro service in such a way that the new equilibrium occurs at a higher level of road congestion than before the increase in capacity. We also confirm that the size of the population matters, in the sense that coordination on the equilibrium route choice realizes more often with a smaller commuter population size. Finally, we find that coordination on the equilibrium route choice occurs more often when the constant cost pricing scheme is adopted.

The paper proceeds as follows. In Section 2 we describe how our study relates to some of the existing literature on both route choice and market entry/coordination games. Section 3 presents the basic model of route choice which is used to parameterize the experiment. The experimental design and procedures are described in Section 4, and the results are contained in Section 5. Section 6 concludes.

\section{Literature Review}

Several experimental papers have examined route choice behavior, per se. Selten et al. (2007) conduct a route choice experiment where subjects choose between two congestible routes. ${ }^{4}$ They find that, despite persistent fluctuations, the mean number of travelers along each route is close to equilibrium. Helbing (2004) modifies Selten et al.'s setup to find that the volatility in subjects' decisions can be reduced by providing either user-specific route recommendations, or information on the potential payoffs from alternate route choices. Chmura and Pitz (2004a and 2004b) consider a game where only the travelers along the least congestible route earn positive payoffs, while all others earn nothing. Similar to Selten et al., they find that overall route stickiness yields higher aggregate payoffs. Gabuthy et al. (2006) and Anderson et al. (2008) use a traffic network with two routes to examine whether a pricing mechanism or toll could reduce congestion to the socially optimal level. Schneider and Weimann (2004), Rapoport et al. (2004) and Ziegelmeyer et al. (2008) report laboratory experiments on bottleneck models where subjects choose their departure time along a single route. In particular, the second study finds that the subjects' ability to coordinate is not affected by the size of the population.

\footnotetext{
${ }^{4}$ In our experiment, subjects choose between a road which is assumed to be a congestible route, and the metro which is assumed to be a non-congestible route.
} 
In this study, we focus on the Downs-Thomson paradox, but this paradox is just one example of a situation in which expanding the capacity of a transportation system does not necessarily improve its performance. Other well-known traffic paradoxes are the Pigou-Knight-Downs paradox and the Braess paradox. The first paradox considers the case where improving the capacity along the congestible route attracts more users and leads to no reduction in travel cost. The Braess Paradox is similar to the Downs-Thomson paradox in the sense that attempt at improving the route capacity - adding a costless link between two alternative routes - yields not only dissipated benefits from improvement, but can actually increase the travel cost for all users (see, Arnott and Small, 1994 for more details). Morgan et al. (2009) consider network changes based on the latter two paradoxes, and similar to our study, find adjustments in traffic flows commensurate with attaining equilibrium (rather than social efficiency). Rapoport et al. (2006, 2008, 2009) also examine the Braess paradox under different information and cost conditions.

To the best of our knowledge, there is only one other study on the Downs-Thomson paradox. Denant-Boèmont and Hammiche (2010) examine a modified version of the Downs-Thomson paradox in which commuters choose between a road and a public transit option, after the operator chooses the capacity of the public transit system. They do find evidence for the Downs-Thomson paradox; but because in the experiment, the capacity of the public transit system is endogenous, it is difficult to isolate the impact of changing road capacity on commuter route choices versus varying transit capacity. Furthermore, the assumption that the operator determines the transit capacity at the start of each period may not reflect the reality of the public transit system operations. In the short run, it is likely that the public transit system operators are committed to a given capacity which cannot be easily adjusted. Therefore, in our experiment we assume that the public transit capacity is exogenously determined, and is fixed within a treatment. We then focus on the commuters' choices between a road and a metro.

We can also draw parallels between a market entry game and a coordination game to the route choice problem studied in this paper. In market entry games, players have the choice either to enter a market or to stay out. The payoff from entering the market is decreasing in the number of entrants, and the payoff from staying out is a constant opportunity cost. In our setup, players have to choose one of the two routes (i.e., the 
choice of staying out is not an option), and while the payoff from choosing the road is decreasing in the number of users, the payoff from choosing the metro actually increases with the number of users. Thus, unlike market entry games, entry along either route generates a strictly positive or a strictly negative externality. Furthermore, in coordination games, players have to coordinate on an equilibrium by choosing an appropriate strategy. In our route choice game, on the other hand, players have to sort themselves between the two routes in a coordinated fashion, so that in equilibrium individuals' payoffs are equalized. Many such equilibria are feasible. Finally, the specific cost function used for the metro brings to mind coordination games in which individuals' payoffs from choosing an action are positive only if a critical mass of players chooses that action. In the context of our route choice game, we will also test how the size of the population may affect coordination along the two routes.

\section{Theoretical model and testable hypotheses}

\section{Basic Setup}

Consider a group of $n$ commuters who must simultaneously and independently choose between two routes - a Road and the Metro. The road represents private transportation where transit time is an increasing function of congestion. Therefore, travel cost on the congestible road is given by

$$
T_{R}=a+b x,
$$

where $x$ is the number of commuters who choose the road, and $a$ and $b$ are positive parameters. The fixed parameter $a$ represents the minimum time it takes to get to the destination using the road, in the absence of any congestion. The congestion parameter $b$ measures the marginal effect on travel time generated by each additional road user. ${ }^{5}$

The metro, on the other hand, represents public transportation where travel cost is inversely related to the number of commuters. In particular, we assume that there is a

\footnotetext{
${ }^{5}$ Assuming a linear cost structure is common in the literature (see Selten et al. 2007; Morgan et al. 2009; Rapoport et al. 2005). Steinberg and Zangwill (1983) note that linear cost approximation is supported by empirical studies on transportation networks.
} 
discrete increase in travel cost of the metro as the number of metro users decreases beyond a certain threshold level, $k$ :

$$
T_{M}= \begin{cases}\mathrm{t}_{1} & \text { if } x \leq k \\ \mathrm{t}_{2} & \text { if } x \geq k+1,\end{cases}
$$

with $t_{1}<t_{2}$. That is, travel cost of the metro is low $\left(=t_{1}\right)$ when no more than $k$ commuters choose the road, and the remaining $(n-k)$ choose the metro; and increases to $t_{2}$ as the road becomes more congested and fewer commuters chose the metro. This "average cost" pricing structure effectively captures the situation in which shifts away from the public transportation mode causes disinvestment in the mode because the service operator either reduces the frequency of service or raises fares to cover costs. ${ }^{6}$

In equilibrium, commuters will sort themselves between the two alternatives until travel cost is equalized along both routes (otherwise at least one commuter could decrease her travel cost by switching routes). Thus, in equilibrium we have $T_{M}=T_{R}$ and solving for $x^{*}$, the equilibrium number of road users, we get

$$
x^{*}=\left\{\begin{array}{l}
\frac{t_{1}-a}{b} \text { if } \frac{t_{1}-a}{b} \leq k \\
\frac{t_{2}-a}{b} \text { if } \frac{t_{2}-a}{b} \geq k+1 .
\end{array}\right.
$$

Since $t_{1}<t_{2}$, it follows that the equilibrium in which fewer number of commuters choose the road $\left(x^{*} \leq k\right)$ Pareto dominates the equilibrium in which the number of road users exceeds $k+1$. $^{7}$

\footnotetext{
${ }^{6}$ As anyone who has stood throughout a long metro ride can attest, there is a point after which the cost of metro increases with greater use intensity. In our analysis, we do not consider this end of the cost spectrum.

${ }^{7}$ Notice that $x^{*}$ is not the efficient number of road users. In fact, the equilibrium number of road users is exactly double the efficient or socially optimal level. Suppose, for example, that $x(\leq k)$ commuters choose the road and the remaining $(n-x)$ choose the metro, then minimization of the aggregate travel cost of the entire commuter population: $x(a+b x)+(n-x) t_{1}$ leads to $x_{1}^{* *}=\frac{t_{1}-a}{2 b}=\frac{x_{1}^{*}}{2}$ commuters choosing the road. If, on the other hand, $x(\geq k+1)$ commuters choose the road, then the optimal number of road users is $x_{2}^{* *}=\frac{t_{2}-a}{2 b}=\frac{x_{2}^{*}}{2}$. The result that the efficient number of road users is half the equilibrium rate is consistent with the notion that when users individually try to minimize their personal cost, they fail to internalize the social cost their decisions impose on others. However, the efficient outcome does not constitute an equilibrium because there is always an incentive for any individual commuter to switch to the road.
} 
Furthermore, given that any combination of $x^{*}$ road users and $n-x^{*}$ metro users constitutes an equilibrium, there exists $C_{x^{*}}^{n}=\frac{n !}{x^{*} !\left(n-x^{*}\right) !}$ such pure strategy equilibrium combinations. ${ }^{8}$ Also, while all pure strategy equilibria predict the same aggregate number of commuters on each route, they do not predict the route chosen by any given commuter.

In addition to pure strategy equilibria, we also consider symmetric mixed strategy equilibrium. Suppose the probability that $s$ other commuters choose road is $p$, then commuter i's expected payoff from choosing the road is

$$
\sum_{s=0}^{\mathrm{n}-1} p^{s}(1-p)^{(n-1-s)}(a+b(s+1)) \frac{n-1 !}{s !(n-1-s) !},
$$

while the expected payoff from choosing the metro is

$$
\sum_{s=0}^{\mathrm{k}} p^{s}(1-p)^{(n-1-s)} \times t_{1} \times \frac{n-1 !}{s !(n-1-s) !}+\sum_{\mathrm{s}=\mathrm{k}+1}^{\mathrm{n}-1} p^{s}(1-p)^{(n-1-s)} \times t_{2} \times \frac{n-1 !}{s !(n-1-s) !} .
$$

Equating the two expected payoffs above, we can solve for $p^{*}$, the equilibrium probability of choosing the road. This equilibrium determination entails that if all commuters choose randomly, they will choose the road with the same probability $p^{*}$; and the standard deviation of the number of commuters on the road is $\sqrt{n p^{*}\left(1-p^{*}\right)}>0$.

Finally, there are also asymmetric mixed strategy equilibria in which some commuters randomize between the two routes, while others stick to a particular route. With $n$ commuters and 2 choices, this yields $2^{n}$ possibilities. Each of these cases constitutes an equilibrium except for the case in which no commuter chooses the road. Thus, there are $2^{n}-1$ possible asymmetric mixed strategy equilibria. It is important to note that despite their multiplicity, these equilibria afford little heterogeneity to commuters. This is because in equilibrium, all commuters who randomize between the road and the metro have to do so with the same probability (Morgan et al. 2009).

We use this basic setup to examine how changes to the road capacity, commuter population size and the metro pricing scheme influence the commuters' route-choice

\footnotetext{
${ }^{8}$ In addition, there are $C_{x^{*-1}}^{n}=\frac{n !}{\left(x^{*}-1\right) !\left(n-x^{*}+1\right) !}$ weak pure strategy equilibria in which $x^{*}-1$ commuters choose the road and $n-x^{*}+1$ commuters choose the metro.
} 
behavior. We begin by providing the motivation for each variation and then detail the parameter specification used in our laboratory setting.

1. Improvement to road capacity. The standard policy reaction to road congestion is to “build our way out” (Arnott and Small, 1994). However, increased road capacity can divert commuters to the congestible road and this diversion may worsen the metro service in such a way that a new equilibrium can only occur where the congestion is worse than before. This swing in the number of commuters towards the improved road underlies the Downs-Thomson paradox, and forms the central question of our investigation.

2. Change in the size of the commuter population, $\boldsymbol{n}$. As stated in Section 2 , there are strong parallels between coordination games and our route choice problem. Past research on coordination games suggests that the number of players is a crucial variable, and coordination steadily gets worse with larger groups (see for example, Knez and Camerer 1994, Goeree and Holt 2005a, VanHuyck et al. 2007). The primary explanation for this trend is the increase in the 'cognitive load' on the players as their beliefs about others' behavior becomes increasingly ambiguous with the introduction of additional players. We examine the extent to which strategic uncertainty, that exists whenever a player lacks perfect foresight about what other players are going to do, influences his/her route choice behavior. $^{9}$

3. Pricing Structure of the Metro. In the basic setup we use a step cost function for the metro. This allows us to capture the strong economies of scale realized as the number of metro users increase. These economies may arise due to two reasons: savings for the operator when the service is more fully utilized and savings for the users when the frequency of service is increased. By employing the pricing structure as an experimental parameter, we provide an improvement to most of the previous traffic studies that assume a constant pricing schedule, i.e. the alternative to the congested road is always a route with a fixed travel cost (see, for example, Selten et al. (2007), Morgan et al. (2009), Rapoport et al., 2009).

\footnotetext{
${ }^{9}$ The above cited studies examine the impact of population size in minimum-effort coordination games. Ziegelmeyer et al. (2008) is the only study on traffic congestion to consider number of commuters as an experimental parameter. However, they examine the impact of population size in a bottleneck model where commuters have to choose their departure time in order to reach a common destination.
} 


\section{Experimental Parameters and Testable Hypotheses}

Throughout the remaining text, we use the following terminology to indicate our four experimental treatments: $\mathrm{ACxx} / \mathrm{CCxx}$ refers to average cost/constant cost pricing structures with $\mathrm{xx}$ depicting the number of subjects per session $(\mathrm{xx}=16$ or 10$)$. AC'16 refers to a treatment with modified average cost pricing and 16 subjects.

AC16: We use the following parameters to characterize the route-choice game in our basic setup:

$$
n=16, a=100, b=12.5, t_{1}=150, t_{2}=225 \text { and } k=7 .
$$

Equalization of travel costs along the road and the metro results in an equilibrium number of road users at two levels: $x_{1}^{*}=4$, with travel cost equal to 150 , and $x_{2}^{*}=10$, with travel cost equal to 225. In the symmetric mixed strategy equilibrium, each commuter chooses the road with probability 0.2 , the expected travel cost is 150.34 and the expected number of road users is 3.2 (with standard deviation of 1.6).

AC'16: Improvement in the road service is parameterized by changing $a$ and $b$ to 40.83 and 14.17 , respectively: ${ }^{10}$

$$
n=16, \boldsymbol{a}=\mathbf{4 0 . 8 3}, \boldsymbol{b}=\mathbf{1 4 . 1 7}, t_{1}=150, t_{2}=225 \text { and } k=7 .
$$

Equalization of travel costs along the two routes results in an increase in the equilibrium number of road users to $x_{\text {improved }}^{*}=13$, and a travel cost equal to 225 . In the symmetric mixed strategy equilibrium, each commuter chooses the road with probability 0.79 . The expected travel cost is 225 and the expected number of road users is 12.64 (with standard deviation of 1.63).

Figure 1 represents the situations detailed in AC16 and AC'16. The improvement in the road capacity is depicted by the downward shift in the road cost curve. This improvement reduces the number of pure strategy equilibria from two to one. More specifically, the Pareto dominated equilibrium of AC16 becomes the unique equilibrium

\footnotetext{
${ }^{10}$ Although the congestion parameter, $b$, has increased, this increase is marginal compared to the large drop in the fixed cost parameter, $a$. We selected these parameter values so that the equilibrium number of commuters on each route is an integer. For our parameter specification, this change entails improved road service for all commuters, as long as the total number of commuters does not exceeds 37.
} 
of AC'16. Our first hypothesis pertains to the realization of this Downs-Thomson Paradox and can be stated as follows:

DT Hypothesis - (comparison of AC16 and AC'16) Congestion, measured in terms of number of road users and total travel cost, increases when the road capacity is increased.

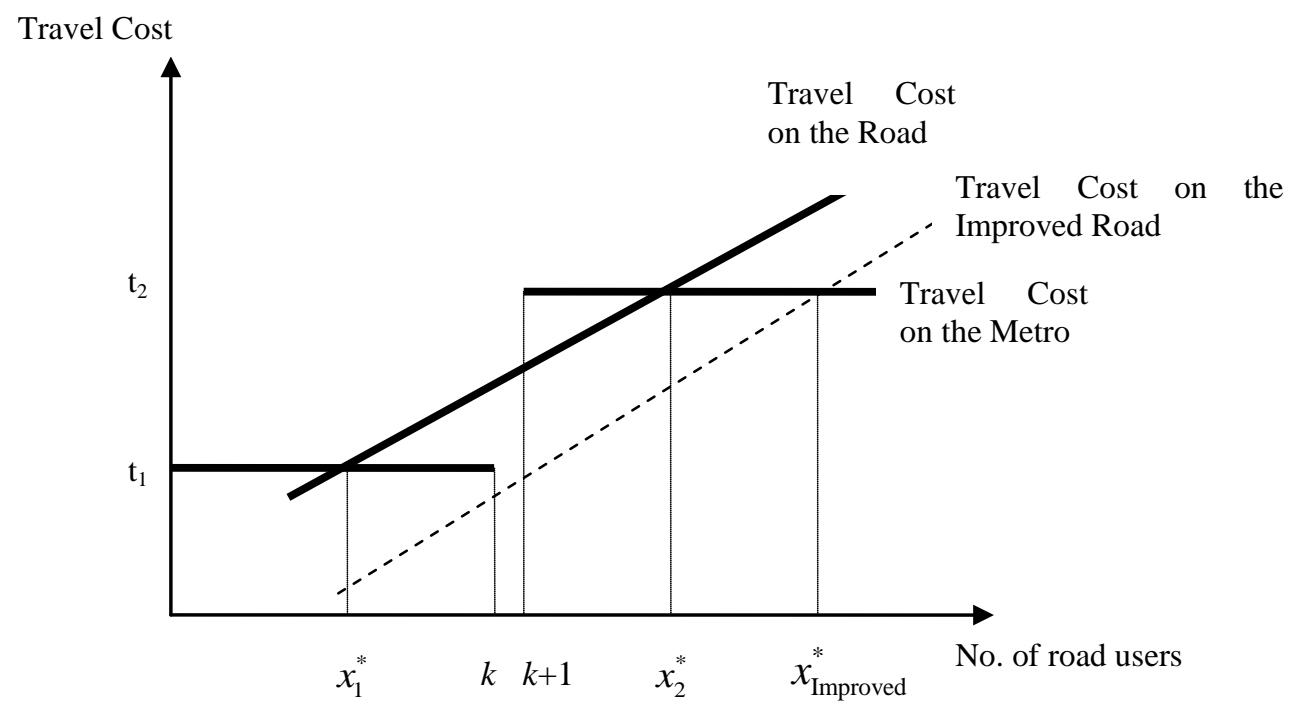

Figure 1. Improved road capacity

AC10. To examine the effect of population size on the commuter route-choice behavior we reduce $n$ from 16 to10. The remaining parameters remain the same as in AC16:

$$
\boldsymbol{n}=10, a=100, b=12.5, t_{1}=150, t_{2}=225 \text { and } k=7 \text {. }
$$

Again, equalization of travel costs along the road and the metro will result in equilibrium number of road users at two levels: $x_{1}^{*}=4$ and $x_{2}^{*}=10$. There are two symmetric mixed strategy equilibria. In one, each commuter chooses the road with probability 0.33 , the expected travel cost is 150.07, and expected number of road users is 3.34 (with standard deviation of 1.49). In the second mixed strategy equilibrium each commuter chooses the road with probability 0.95 , the expected travel cost is 218.98 , and the expected number of road users is 9.46 (with standard deviation of 0.71)

Note that in both AC16 and AC10, the equilibrium number of road users takes two values, $x_{1}^{*}=4$ and $x_{2}^{*}=10$. This means that in both cases there are two mutually consistent ways in which commuters can sort themselves - one more costly than the 
other. The prior literature suggests that this duality in equilibrium prediction gives rise to strategic uncertainty, even though the environment, the feasible strategies and the equilibrium conventions are common knowledge. However, in case of AC10, $x_{2}^{*}=10$ is much harder to realize because it entails that the entire population must coordinate simultaneously on the same, more costly, route. This makes $x_{1}^{*}=4$ the focal equilibrium in AC10, while both equilibria are equally viable in AC16. Our next hypothesis examines the impact of a decrease in the size of the commuter population on coordination behavior in general, and on the selection of the Pareto dominant equilibrium in particular, and can be stated as follows:

Size Hypothesis - (comparison of AC16 and AC10) There is greater coordination on the equilibrium route choice when the size of the commuter population is relatively small. Congestion, as measured by the number of road users and total travel cost, may decrease.

CC10: To examine the effect of different pricing structures for the metro on the commuter route-choice behavior we consider the same parameters as in AC10, but change $\mathrm{T}_{\mathrm{M}}$ to the uniform rate of $\left(t_{1}+t_{2}\right) / 2=180$ :

$$
n=10, a=100, b=12.5, \mathbf{T}_{\mathbf{M}}=\mathbf{1 8 0} \text {, and } k=7 \text {. }
$$

Equalization of travel costs along the road and the metro will result in a unique equilibrium number of road users, $x^{*}=6$. In the symmetric mixed strategy equilibrium, each commuter chooses the road with probability 0.6 , the expected travel cost is 180 and the expected number of road users is 6 (with standard deviation of 1.55).

Figure 2 represents the impact of this change in the metro pricing structure on the commuters' equilibrium coordination behavior. Equalization of travel costs along the two routes implies that the average cost pricing structure, approximated by a step cost function, yields two possible equilibria; while the constant cost pricing structure yields only one equilibrium. Accordingly, we test whether the existence of a second, though dominated, equilibrium makes coordination in route choice more difficult. Also, and perhaps more importantly from a policy point of view, we seek support for the conjecture that average cost pricing of the metro reduces road congestion. The impact of the pricing 
structure on both coordination and congestion generates our last hypothesis which can be stated as follows:

Price Hypothesis - (comparison of AC10 and CC10) There is greater coordination on the equilibrium route choice when the uniform pricing structure is adopted on the alternative (metro) route. However, congestion, as measured by the number of road users and total travel cost, is higher.

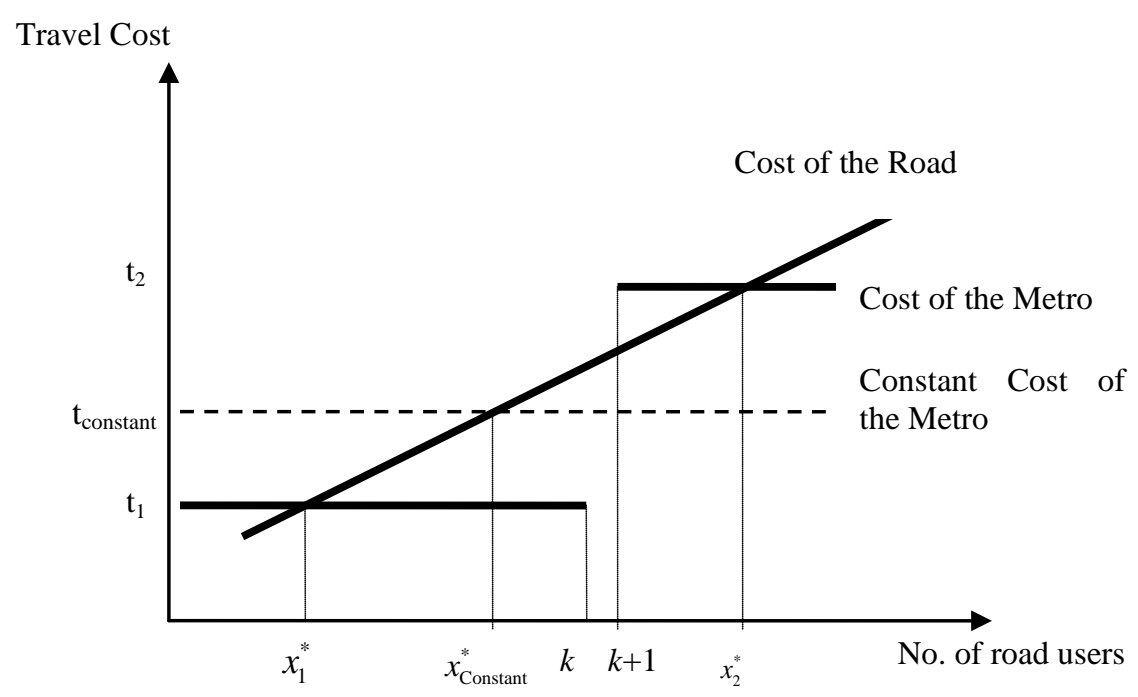

Figure 2. Average cost vs. constant cost pricing of the metro.

Table 1 summarizes the parameters used in the four cases and the corresponding pure-strategy equilibrium predictions. We use this as a basis for our experimental design, which is detailed in the next section. 


\begin{tabular}{|c|c|}
\hline AC16 & AC'16 \\
\hline $\boldsymbol{n}=\mathbf{1 6} \quad \mathbf{T}_{\mathbf{R}}=100+12.5 x$ & $\boldsymbol{n}=\mathbf{1 6} \quad \mathbf{T}_{\mathbf{R}}=40.83+14.17 x$ \\
\hline $\mathrm{T}_{\mathrm{M}}=\mathrm{t}_{1}(150)$ or $\mathrm{t}_{2}(225)$ & $\mathrm{T}_{\mathrm{M}}=\mathrm{t}_{1}(150)$ or $\mathrm{t}_{2}(225)$ \\
\hline Equilibrium road users: 4 or 10 & Equilibrium road users: 13 \\
\hline Equilibrium travel cost: 150 or 225 & Equilibrium travel cost: 225 \\
\hline AC10 & CC10 \\
\hline $\boldsymbol{n}=\mathbf{1 0} \quad \mathrm{T}_{\mathrm{R}}=100+12.5 x$ & $\boldsymbol{n}=\mathbf{1 0} \quad \mathrm{T}_{\mathrm{R}}=100+12.5 x$ \\
\hline $\mathrm{T}_{\mathrm{M}}=\mathrm{t}_{1}(150)$ or $\mathrm{t}_{2}(225)$ & $\mathbf{T}_{\mathbf{M}}=\left(\mathrm{t}_{1}+\mathrm{t}_{2}\right) / 2=180$ \\
\hline Equilibrium road users: 4 or 10 & Equilibrium road users: 6 \\
\hline Equilibrium travel cost: 150 or 225 & Equilibrium travel cost: 180 \\
\hline
\end{tabular}

Table 1. Pure strategy equilibrium prediction for all cases

\section{Experimental Design and Procedures}

The experiment consists of 14 sessions conducted at Virginia Commonwealth University in 2008 using the program z-Tree (Fischbacher, 2007). A total of 176 subjects recruited from introductory economics and business classes participated in the experiment. All subjects were inexperienced in this decision-making environment and no one participated in more than one session. Upon arrival, subjects were randomly seated at computer terminals and given a set of instructions (included in the Appendix), which were later read aloud by the experimenter. Throughout the session, no communication between subjects was permitted and all choices and information were transmitted through computer terminals. At the end of the session, subjects received their total profit from the experiment, and were paid privately and in cash. Earnings were converted from experimental dollars to U.S. dollars using a pre-determined conversion rate. The sessions 
usually lasted about 40-45 minutes and the average earnings were approximately $\$ 21$, excluding the \$3 show-up fee.

In all sessions, 10 or 16 subjects made route-choice decisions over 40 periods. A typical period proceeded as follows: each subject (assigned the role of a commuter) travelled to some destination D, by choosing one of two routes, labeled A and B. ${ }^{11}$ Travel along both routes is costly and depends on the number of other commuters choosing the same route. We assume that travel costs are common knowledge and, therefore, display them on the subjects' computer screen every period. Upon reaching destination D, subjects receive 275 experimental dollars minus their travel cost. At the end of each period, subjects receive a summary of the number of commuters on each route, their period payoff and their total payoff so far. We provide subjects with complete information to increase their opportunity to learn about others' strategies, and also to provide them with sufficient information to calculate the optimal route choice ex-post. ${ }^{12}$

Table 2 summarizes our experimental design. In accordance with the cases detailed in the previous section, we vary three experimental parameters: road capacity (DT treatment), pricing structure of the metro (pricing treatment), and the size of commuter population (size treatment). To examine the impact of each variation, all experimental sessions consisted of two sequences of 20 periods each, with each sequence featuring a specific case paradigm. Having the same set of subjects make decisions for two different cases controls for subject variability and allow the effect of change to be assessed by a within session comparison. However, experience in the first 20 periods can affect the

\footnotetext{
${ }^{11}$ The instructions and decision screens refer to choices as Route A and Route B. We use this transportation terminology to help subjects more readily understand the decision they face. However, to prevent personal biases from influencing the results, we do not make any reference to the 'public transit' option. The terminology is held constant across all sessions, so framing cannot affect the conclusions regarding comparative static hypotheses that are the focus of this research.

${ }^{12}$ Most experiments on traffic (Helbing 2004, Ziegelmeyer et al. 2008, Rapoport et al. 2009) and market entry games (Sundali et al. 1995), with the notable exception of Morgan et al. (2009), provide subjects with the precise description of the associated costs. Duality of equilibrium prediction in our setup creates strategic uncertainty and Helbing (2004) conjecture that improved information could facilitate better "adaptation performance." Therefore, to create conditions most conducive to coordination and to be consistent with the literature, we provide subjects with the entire cost structure. It is important to bear in mind that even with complete information of the underlying cost, coordination of 10 to 16 subjects on a particular strategy is by no means trivial. Nevertheless, as a robustness check, we did run two additional sessions where subjects were not informed about the entire cost schedule and only knew the minimum and maximum possible travel cost for Route A. There is no statistical difference between the complete and incomplete information treatments (see also footnote 13). Details for the incomplete information sessions are available from the authors upon request.
} 
subjects' behavior in the following 20 periods. Therefore, we switched the sequence order to measure and control for such experience effects. Consider, for example, sessions 1-6 that test the DT hypothesis. The first sequence in sessions 1-3 featured AC16 and was followed by AC'16; sessions 4-6 reversed the ordering and began with AC'16. A similar design is used in sessions 7-14 that test the price hypothesis. Finally, we test the size hypothesis using across session comparisons with two different population sizes, $n=16$ and $n=10$. Sessions 1-6 employed 16 subjects each. For the remaining sessions, we employed a cohort of 20 subjects and simultaneously ran 2 sessions of 10 subjects each. There was no interaction across the two groups in the cohort and subjects remained matched with the same participants for the entire length of the experiment.

\begin{tabular}{|l|l|}
\hline \hline \multirow{3}{*}{ DT Treatment } & $\begin{array}{l}\text { Within session comparison of AC16 and AC'16: } 6 \text { sessions. } \\
\text { Sessions 1-3: } 20 \text { periods of AC16 followed by } 20 \text { periods of AC'16. } \\
\text { Sessions 4-6: Sequencing reversed. } \\
\text { Total number of subjects: } 96 \\
\text { Number of subjects per session: } 16\end{array}$ \\
\hline Price Treatment & $\begin{array}{l}\text { Within session comparison of AC10 and CC10: } 8 \text { sessions. } \\
\text { Sessions 7-10: } 20 \text { periods of AC10 followed by } 20 \text { periods of CC10. } \\
\text { Sessions 11-14: Sequencing reversed. } \\
\text { Total number of subjects: } 80 \\
\text { Number of subjects per session: } 10\end{array}$ \\
\hline Size treatment & $\begin{array}{l}\text { Across session comparison of AC16 and AC10: } 7 \text { sessions } \\
\text { Sessions 1-3: First } 20 \text { periods of AC16. No. of subjects per session: } 16 \\
\text { Sessions 7-10: First } 20 \text { periods of AC10. No. of subjects per session: } 10 \\
\text { Total number of subjects: } 88\end{array}$ \\
\hline
\end{tabular}

Table 2. Experimental design

\section{Results}

We have a panel dataset of route choice decisions made by 176 subjects over 40 periods across 14 sessions and under four case paradigms. Table 3 reports the summary statistics for each session. We use two measures of performance: aggregate route choice 
(or, the average number of road users) and the average travel cost. In all four cases, the aggregate choice behavior moves in accordance to the theoretical prediction. However, there are persistent and substantial fluctuations, as is evident in Figure 3. In the formal statistical analysis discussed below we begin by focusing on the equilibrium comparison and the individual choice behavior. Next, we provide formal support for all of the comparative statics hypotheses. Finally, we show that the Quantal Response Equilibrium provides an excellent fit of the aggregate route choice behavior. To account for the treatment switchover effect and the possible hysteresis, we restrict our analysis to the last 15 periods of each sequence run.

\subsection{Equilibrium Comparison}

The theoretical model predicts the equilibrium number of road users (or equivalently, the travel cost on each route). In AC16 and AC10, of the two Nash equilibria, the Pareto dominant equilibrium entails that 4 commuters use the road. The left half of Table 3 shows that there are systematically more road users than the Pareto dominant equilibrium in both of these cases. The number of road users is higher than predicted in all 6 sessions featuring AC16 and in 6 out of the 8 sessions featuring AC10. Consequently, conservative non-parametric tests based on one observation from each of these statistically independent sessions support the alternative hypothesis that there are significant differences between observed and equilibrium route choice behavior (twosided Wilcoxon sign-rank test: AC16: $n=6, z=2.21, p$-value $=0.03$; AC10: $n=8, z=$ $1.76, p$-value $=0.08)$. The analysis of average travel cost yields similar results. Thus, in both AC16 and AC10 there is greater traffic flow along the congestible road, which results in higher average travel cost for all commuters. It is possible that the presence of the additional (albeit Pareto dominated) equilibrium of 10 road users affects behavior. However, in Table 3, we find that the average number of road users is closer to the Pareto dominant equilibrium in all sessions of AC10 (4.15) and in all but one session of AC16 (6.13). Therefore, in the rest of the analysis of AC16 and AC10 treatments, we focus only on the Pareto dominant equilibrium of 4 road users.

The right half of Table 3 shows the corresponding data for AC'16 and CC10. Recall that in both cases, the equilibrium is unique and predicts a larger number of road users 
(13 in AC'16 and 6 in CC10). As before, we find that the observed number of road users is significantly different from the predicted level. However, unlike the previous two cases, now there are systematically fewer road users and, accordingly, the average travel cost is lower than predicted (sign-rank test: AC'16: $n=6, z=-2.21, p$-value $=0.03$; CC10: $n=8, z=-1.90, p$-value $=0.06){ }^{13}$

In summary, the observed number of road users is higher than predicted when the Pareto dominant equilibrium predicts few users (AC16 and AC10), and lower than predicted when equilibrium predicts many users (AC'16 and CC10). The deviation from equilibrium in the direction of a more even allocation of commuters along the two routes is also noted by Morgan et al. (2009). These results are also consistent with the prior experimental literature on market entry games. In his review, Camerer (2003) notes that there is a slight tendency towards over-entry when equilibrium predicts few entrants and under-entry when equilibrium predicts many entrants.

A key feature of the equilibrium is the equalization of travel cost along the two routes. Table 3 reports the average difference in travel cost between the road and the metro. Since the number of commuters on the congestible road is systematically higher than predicted in AC16 and AC10, the road is significantly more costly than the metro in these cases; the opposite holds true for AC'16 and CC10 where the road is the cheaper alternative. ${ }^{14}$ Of course, this rejection of the "equalized travel cost hypothesis" in all four cases is consistent with the previous observation that the number of users along each route is systematically different from predicted.

\footnotetext{
${ }^{13}$ In reference to footnote 12 , these results are confirmed even in the no information treatment. When subjects did not have complete information about the underlying cost structure for Route A, the observed number of road users and the total travel were significantly higher than the Pareto dominant equilibrium in AC16 (6.34 and 176.52, respectively) and significantly lower in AC'16 (10.58 and 201.91, respectively).

${ }^{14}$ Two-sided Wilcoxon sign-rank test - for AC16: $n=6, z=1.99, p$-value $=0.05$; AC'16: $n=6, z=-2.20$, $p$-value $=0.03$; AC10: $n=8, z=1.83, p$-value $=0.07$; CC10: $n=8, z=-2.52, p$-value $=0.01$.
} 


\begin{tabular}{|c|c|c|c|c|c|c|c|}
\hline $\begin{array}{l}\text { Case \# - } \\
\text { Session \# }\end{array}$ & $\begin{array}{c}\text { Average } \\
\text { no. of } \\
\text { road } \\
\text { users }\end{array}$ & $\begin{array}{c}\text { Average } \\
\text { travel } \\
\text { cost }\end{array}$ & $\begin{array}{c}\text { Diff. in } \\
\text { cost } \\
\text { (road- } \\
\text { metro) }\end{array}$ & $\begin{array}{l}\text { Case \# - } \\
\text { Session \# }\end{array}$ & $\begin{array}{c}\text { Average } \\
\text { no. of } \\
\text { road } \\
\text { users }\end{array}$ & $\begin{array}{c}\text { Average } \\
\text { travel } \\
\text { cost }\end{array}$ & $\begin{array}{c}\text { Diff. in } \\
\text { cost } \\
\text { (road- } \\
\text { metro) }\end{array}$ \\
\hline AC16 - 1 & 5.67 & 170.83 & 20.83 & AC'16 - 1 & 10.87 & 194.81 & -25.19 \\
\hline AC16 - 2 & 5.87 & 173.33 & 8.33 & AC'16 - 2 & 11.2 & 199.53 & -25.47 \\
\hline AC16 - 3 & 6 & 175 & 15 & AC'16 - 3 & 12.27 & 214.65 & -10.35 \\
\hline AC16 - 4 & 5.67 & 170.83 & 10.83 & AC'16 - 4 & 9.47 & 174.97 & -30.03 \\
\hline AC16 - 5 & 8.6 & 207.5 & -7.5 & AC'16 - 5 & 11.33 & 201.42 & -18.58 \\
\hline AC16 - 6 & 5 & 162.5 & 12.5 & AC'16 - 6 & 10.2 & 185.36 & -29.64 \\
\hline $\begin{array}{l}\text { Overall } \\
\text { Average }\end{array}$ & 6.13 & 176.67 & 10 & $\begin{array}{l}\text { Overall } \\
\text { Average }\end{array}$ & 10.89 & 195.13 & -23.21 \\
\hline $\begin{array}{l}\text { Theoretical } \\
\text { Prediction }\end{array}$ & $4 / 10$ & $150 / 225$ & 0 & $\begin{array}{l}\text { Theoretical } \\
\text { Prediction }\end{array}$ & 13 & 225 & 0 \\
\hline AC10 - 7 & 4.13 & 151.67 & 1.67 & CC10 - 7 & 5.73 & 171.67 & -8.33 \\
\hline AC10 - 8 & 4.33 & 154.17 & 4.17 & CC10- 8 & 3.87 & 148.33 & -31.67 \\
\hline AC10 - 9 & 3.8 & 147.5 & -2.5 & CC10 - 9 & 4.8 & 160 & -20 \\
\hline AC10 - 10 & 4.27 & 153.33 & 3.33 & CC10 - 10 & 4.53 & 156.67 & -23.33 \\
\hline AC10 - 11 & 4.4 & 155 & 5 & CC10 - 11 & 5.27 & 165.83 & -14.17 \\
\hline AC10 - 12 & 4 & 150 & 0 & CC10 - 12 & 4.8 & 160 & -20 \\
\hline AC10 - 13 & 4.07 & 150.83 & 0.83 & CC10 - 13 & 6.33 & 179.17 & -0.83 \\
\hline AC10 - 14 & 4.2 & 152.5 & 2.5 & CC10 - 14 & 6.27 & 178.33 & -1.67 \\
\hline $\begin{array}{c}\text { Overall } \\
\text { Average }\end{array}$ & 4.15 & 151.88 & 1.88 & $\begin{array}{c}\text { Overall } \\
\text { Average }\end{array}$ & 5.2 & 165 & -15 \\
\hline $\begin{array}{l}\text { Theoretical } \\
\text { Prediction }\end{array}$ & $4 / 10$ & $150 / 225$ & 0 & $\begin{array}{l}\text { Theoretical } \\
\text { Prediction }\end{array}$ & 6 & 180 & 0 \\
\hline
\end{tabular}

\section{Table 3. Summary statistics}

The above non-parametric tests are valuable because they require a minimal number of statistical assumptions and are based only on statistically independent observations. However, they cannot control for factors such as time trend and subject heterogeneity that could influence the results (see Figure 3). Therefore, we also conduct multivariate regression models with subject level random effects. These regressions include a control 
for time trend, as well as session and sequence dummies to capture the fixed effects. The regression equation for case $i$ is

$$
x_{t}^{i}-x^{*}=\alpha+\beta(1 / t)+\delta d+\lambda s+\varepsilon_{t},
$$

where $x_{t}^{i}-x^{*}$ is the difference between the observed number of road users in period $t$ and the equilibrium prediction for case $i, d$ is the sequence dummy, $s$ is the vector of session dummies, and $\varepsilon$ is the composite error term. The regression results largely corroborate the conclusions from the non-parametric tests in the case of a large commuter population. In particular, the number of road users is significantly different from the prediction. It is higher than predicted in AC16 ( $t$-statistic $=10.64, p$-value $<0.01)$ and lower than predicted in AC'16 ( $t$-statistic $=-7.95, p$-value $<0.01$ ). However, when the commuter population is 10 , the parametric results differ in the sense that the observed number of road users is marginally lower than predicted in AC10 ( $t$-statistic $=-2.09, p$ value $=0.04)$ and it is not statistically different in CC10 (t-statistic $=-0.62, p$ value $=0.53) .{ }^{15}$

A striking feature of our data is the persistent variability in traffic flows. Even in the long run, route choices display considerable variability resulting in higher average travel cost for all commuters. Both Selten et al. (2007) and Morgan et al. (2009) invoke mixed strategy play as an explanation for these fluctuations. Next, we compare our results to the symmetric mixed strategy equilibrium, which predicts the probability that a commuter chooses the road and, therefore, the expected number of road users, as well as the standard deviation of the number of road users per period. In all but one case, the observed number of road users is significantly different from the mixed strategy prediction. In case of AC16 and AC10, the mixed strategy equilibrium under-predicts the number of road users ( $p$-value $<0.01$ ), while in case of AC'16 the number of observed road users is lower than predicted ( $p$-value $<0.01$ ). Similar to the pure strategy

\footnotetext{
${ }^{15}$ Despite concentrating on the last 15 periods of each sequence run, we find that the time trend is significant in all four cases. With the sole exception of CC10, the difference between the observed and the predicted number of road users declines over time (also see Figure 3). Results are similar irrespective of whether $\ln$ (period) or 1/period is used to control for the time trend. We also find that sequence dummies are significant at the 1 percent level in all cases, except in the AC10 treatment (p-value $=0.64$ ). In the AC16 and CC10 treatments, the difference from the equilibrium prediction is lower when the treatment is featured as the second sequence, while the opposite is true in the AC'16 treatment. Regressions are available from the authors upon request.
} 
equilibrium, only in case of CC10 does the data correspond to the symmetric mixed strategy prediction $(p$-value $=0.53)$. To compute the standard deviation, we treat the number of road users in a given period as an observation. In Table 4 we compare the observed standard deviation of road users with the level predicted by the symmetric mixed strategy (described in Section 2). In all cases except CC10 ( $p$-value $=0.28$ ), the mixed strategy prediction is significantly different from the data. In case of AC16 and AC'16, the equilibrium under-predicts the variability ( $p$-value $<0.01$ in both cases) and in case of AC10, the equilibrium over-predicts the variability in route choices ( $p$-value < 0.05).

Figure 7 presents the time series of the average number of route changes in all four cases. There is no significant difference in the route change behavior when the population size is kept constant. Furthermore, although the number of route changes seems higher in AC16 and AC'16 $(n=16)$ compared to AC10 and CC10 $(n=10)$, this difference can be entirely attributed to the difference in commuter size. That is, the total number of changes is correspondingly higher in treatments where the commuter population size is larger. Overall, the data show that in a given period, on average, about 30 percent of the commuters' decisions feature a route change. Table 4 includes the statistics of the percentage of times a given commuter changes routes in consecutive periods for all four cases and compares it to the switching propensity as predicted by the symmetric mixed strategy equilibrium. In cases AC16 and AC'16, the mixed strategy equilibrium provides a fairly accurate description of the switching propensity, but in AC10 and CC10, the mixed strategy equilibrium over-predicts the number of road changes. ${ }^{16}$ Looking at individual commuter behavior, we find that in all four cases around 60 percent of the commuters changed route fewer than 5 times in the last 15 periods of play. This route stickiness is a profitable strategy because the commuters' cumulative payoffs are negatively correlated with the number of route changes. ${ }^{17}$ The result that the overall route

\footnotetext{
${ }^{16}$ In Table 4, switching propensity $=$ [probability of road change from one period to the next $*$ number of opportunities for each player * number of players in a session] / total number of possible changes. For instance, in case of AC16, switching propensity $=([2 * 0.2 *(1-0.2)] * 14 * 16) / 14 * 16=0.32$.

${ }^{17}$ This relation is strictly negative in all four cases, but is statistically insignificant for AC'16 ( $p$-value = 0.39). Furthermore, formal non-parametric tests reject the null hypothesis that these correlation coefficients are not significantly different across all treatments.
} 
stickiness yields higher aggregate payoff is also consistent with the results reported by Chmura and Pitz (2004a, 2004b) and Selten et al. (2007).

\begin{tabular}{cc|cccc}
\hline \hline & & AC16 & AC'16 & AC10 & CC10 \\
\hline $\begin{array}{c}\text { Avg. no. of road } \\
\text { users }\end{array}$ & Observed & 6.13 & 10.89 & 4.15 & 5.2 \\
\hline $\begin{array}{c}\text { St. dev. of no. } \\
\text { of road users }\end{array}$ & MSE & 3.2 & 12.64 & 3.34 & 6 \\
\hline $\begin{array}{c}\text { Switching } \\
\text { Propensity }\end{array}$ & Observed & $29.4 \%$ & $29.4 \%$ & $28.7 \%$ & $26.7 \%$ \\
\hline \hline
\end{tabular}

Table 4. Comparison of observed and mixed strategy equilibrium

As a final point, we note that subject behavior is not efficiency-seeking in nature. Efficiency requires that the number of road users be half of the predicted Nash equilibrium level. This necessarily implies unequal travel costs along the two routes. In particular, the social optimum is reached when the congestible road is associated with fewer commuters and, therefore, lower travel costs. However, in all four cases we find that there are significant differences between observed and efficient traffic flows (signrank test $p$-value $<0.01$ in all cases). Similar to the prior literature on traffic (Morgan et al. 2009, Anderson et al. 2008) and market entry games (Sundali et al. 1995, Rapoport et al. 1998) we find that the average number of road users is much closer to the Nash equilibrium number than to the efficient number. Because individuals fail to internalize the social cost their decisions impose on others, their expected travel costs are higher than at the social optimum. We find no evidence that even with experience, players move away from the equilibrium solution in the direction of the socially efficient outcome. With ten or sixteen commuters in a group, cooperation can be quite difficult to achieve, even with repetitions and fixed matching, especially without the ability to communicate. 


\subsection{Comparative Statics}

Next, we focus on the comparative statics embedded in our three hypotheses. Figures 4 through 6 present pair-wise comparison of the time series for equilibrium and observed number of road users in all four cases. The figures give the impression that all three hypotheses are strongly supported by the data. Below, we provide a formal documentation to confirm this visual impression.

DT Hypothesis: A comparison of AC16 and AC'16 generates support for the DT hypothesis. In sessions 1-6, each group of subjects made route choices in both these case paradigms, with the sequence ordering reversed. For within session non-parametric tests, we, therefore, construct statistically independent pair-wise differences using the results shown in Table 3. For instance, in Session 1 the average number of road users is 5.67 for AC16 and 10.87 for AC'16, and so the difference of -5.2 is one of the six statistically independent differences. Since all six differences are negative, as predicted by the model, we can reject the null of zero difference using both a sign test ( $p$-value $=0.03$ ), and a sign-rank test $(z=-2.207, p$-value $=0.03)$. Similar results are obtained using pair-wise differences constructed from the average travel cost. In five of the six sessions, the average travel cost is higher in AC'16 than in AC16 (sign-rank test: $z=1.78, p$-value $=$ 0.07). A random effects model with subject random effects, session and sequence fixed effects and a time trend also strongly rejects the null hypothesis of no increase in road congestion $(t$-statistic $=71.40, p$-value $<0.01)$. Thus, consistent with the DT paradox, we find evidence that improvement in road capacity leads to more road users and higher travel cost for all commuters.

Size Hypothesis: A comparison of AC16 and AC10 generates support for the size hypothesis. In order to mitigate the effect of experiential learning, we concentrate on sessions in which these two cases are featured as the first sequence. That is, we include only sessions 1-3 for AC16 and sessions 7-10 for AC10. In Table 3, the highest average number of road users in AC10 (4.33) is lower than the lowest average number of road users in AC16 (5.67). Therefore, a conservative non-parametric Mann-Whitney test based on one observation from each of these 7 statistically independent sessions reject the null hypothesis that commuter population size does not affect the level of road congestion ( $p$ value $=0.04)$. A comparison based on average difference in travel cost ( $p$-value $=0.04)$ 
and a random effect model specification ( $t$-statistic $=-15.47, p$-value $<0.01$ ) also gives the same result. Hence, consistent with the size hypothesis, we find evidence that road congestion is higher and coordination problem is more severe with a larger commuter population size.

Price Hypothesis: A comparison of AC10 and CC10 generates support for the price hypothesis. Similar to the above analysis, we generate 8 statistically independent pairwise differences using the data from sessions 7-14 (Table 3). Since 7 out of 8 pair-wise differences based on the average number of road users are positive, we find support for the alternative hypothesis that road congestion is worse when the constant cost pricing structure is employed for the metro (sign test: $p$-value $=0.07$, sign-rank: $z=2.24, p$-value $=0.03)$. Pair-wise differences based on average travel cost ( $p$-value $=0.03)$ and random effects model that control for time trend and session and sequence fixed effects ( $t$-statistic $=20.05, p$-value $<0.01$ ) also yield a similar result. Note that while constant cost structure worsens road congestion, the uniqueness of its equilibrium prediction helps alleviate the coordination problem. As detailed in the previous subsection, parametric regressions show that the observed number of road users is not statistically different from the predicted level in case of constant cost pricing (CC10).

\subsection{Quantal Response Equilibrium}

In subsection 5.1, we provided evidence for two types of deviations from the Pareto dominant Nash equilibrium. In AC10 and AC16, where the predicted number of road users is less than half the number of commuters, subjects tend to over-use the road as compared to the equilibrium. In contrast, in CC10 and AC'16, subjects tend to under-use the road. In these treatments, the predicted number of road users is greater than half the number of commuters. This deviation in the direction of a more even allocation of commuters along the two routes is also observed if we compare the observed behavior to the symmetric mixed strategy equilibrium. In entry games and models of political participation, such patterns of over-usage and under-usage are consistent with the Quantal Response Equilibrium (QRE), which assumes that decision-making is prone to errors (Goeree and Holt, 2005b). 
We apply the logit QRE to the model of route choice. To describe the QRE, let $p_{R}$ denote the probability that a player chooses the road. Suppose that $U_{R}$ denotes a player's expected payoff from choosing the road when all other players use the mixed strategy $\left(p_{R}, 1-p_{R}\right)$, and analogously, $U_{M}$ denotes the expected payoff from choosing the metro. Then, in the logit QRE equilibrium

$$
p_{R}=\frac{\exp \left(\mu U_{R}\right)}{\exp \left(\mu U_{R}\right)+\exp \left(\mu U_{M}\right)}
$$

where $\mu>0$ is the error parameter to be estimated. As $\mu$ goes to infinity, $p_{R}$ converges to a mixed strategy Nash equilibrium of the game. As $\mu$ goes to zero, $p_{R}$ goes to one half (Goeree and Holt, 2005b). The intuition behind the model is that the probability, $p_{R}$, enters both the expected payoffs in the logit function on the right-hand side of equation (7) as a "belief," and on the left-hand side as a choice probability. The equilibrium requires that beliefs and choice probabilities are the same. For finite normal form games, McKelvey and Palfrey (1995) show that a QRE equilibrium exists. This equilibrium model has one parameter, $\mu$, which can be estimated from the data via maximum likelihood.

In order to estimate the value of $\mu$, we use individual observations from the last 15 periods of a sequence and we pool together the data from all four treatments. Therefore, the log likelihood function is given by a constant plus

$$
\sum_{i \in T} n(i) \log \left[p_{R}(i)\right]+[N(i)-n(i)] \log \left[1-p_{R}(i)\right]
$$

where $T=\left\{A C 16, A C^{\prime}, A C 10, C C 10\right\}$ is the set of treatments, $N(i)$ is the total number of observations in treatment $i$ and $n(i)$ is the number of road choices observed in treatment $i$. Finally $p_{R}(i)$ is the QRE probability in treatment $i$, which is implicitly given by equation (7) and depends on $\mu$. Table 5 reports the maximum likelihood estimate of $\mu$ as well as the resulting QRE probabilities. ${ }^{18}$ The results show that the predicted QRE probability provides an excellent fit for aggregate observed usage of the road.

\footnotetext{
${ }^{18}$ The estimation is performed in Maple. The code is available from the authors upon request.
} 


\begin{tabular}{|c|c|c|c|c|}
\hline & AC16 & AC'16 & AC10 & CC10 \\
\hline \multicolumn{5}{|l|}{ Probability of road choice } \\
\hline QRE & 0.36 & 0.66 & 0.43 & 0.54 \\
\hline Mixed Strategy Equilibrium & 0.20 & 0.79 & 0.34 & 0.60 \\
\hline \multicolumn{5}{|l|}{ Number of road users } \\
\hline QRE & 5.76 & 10.56 & 4.30 & 5.40 \\
\hline Mixed Strategy Equilibrium & 3.20 & 12.64 & 3.40 & 6.00 \\
\hline Observed & 6.13 & 10.89 & 4.15 & 5.20 \\
\hline \multirow[t]{2}{*}{ Estimate $\hat{\mu}$} & \multicolumn{4}{|c|}{0.028} \\
\hline & \multicolumn{4}{|c|}{$(0.003)$} \\
\hline Log Likelihood & \multicolumn{4}{|c|}{-3511.26} \\
\hline
\end{tabular}

Table 5. Logit QRE results

Figure 8 illustrates the logit QRE in the manner of Goeree and Holt (2005b). Each of the four graphs has the probability of using the road on the horizontal axis and the difference in expected payoffs between the road and the metro on the vertical axis. To construct the figures, note that after rearranging terms, equation (7) can be written as

$$
\mu^{-1} \ln \left(\frac{p_{R}}{1-p_{R}}\right)=U_{R}-U_{M}
$$

where the expected payoff difference, $U_{R}-U_{M}$, is a non-linear function of $p_{R}$. As $p_{R}$ varies, the black curve shows the logit divided by $\mu$ on the left-hand side (LHS) of equation (9) and the red curve shows the payoff difference on the right-hand side (RHS). An intersection between the red curve and the horizontal axis is a mixed strategy equilibrium because $U_{R}-U_{M}=0$, whereas an intersection between the two curves is a QRE. To draw the curves we set $\mu$ equal to its estimated value given in Table 5.

Figure 8 shows that in every treatment, the QRE explains the observed departures from the mixed strategy Nash equilibrium quite well. In AC10 and AC16 the Nash equilibrium predicts a lower frequency of road usage than what was observed. This departure from Nash equilibrium conforms with the QRE prediction. In CC10 and AC'16 we observe the opposite pattern - the frequency of road usage in the data is greater than 
the Nash equilibrium prediction. As Figure 8 shows, the QRE correctly predicts the observed pattern in these two cases as well.

\section{Conclusion}

The aim of this paper is to extend the experimental research on congestible networks in general, and on the Downs-Thomson paradox in particular. We report the results of an experimental analysis of a model of road congestion in a situation where to reach their final destination, commuters must choose between two routes: a congestible Road or an alternative Metro. Travel cost on the road is increasing in the number of commuters who choose it, and travel cost on the metro is decreasing in the number of its users. We examine how changes to road capacity, to the number of commuters and to the metro pricing scheme influence the commuters' route-choice behavior.

We confirm our hypotheses. By changing the road capacity, we verify the realization of the Downs-Thomson paradox. In particular, we find that improving the road capacity leads to more commuters switching to the road, thereby increasing the travel costs for commuters on all routes, including the alternative metro. Thus, not only the benefits from improving the road service are completely dissipated, but the benefits inherent to the mass transit service also are thwarted, and society as a whole is worse off. By changing the metro pricing scheme we examine the extent to which average cost pricing is responsible for causing the Downs-Thomson paradox. Unlike previous experimental studies that assume constant cost structure for the alternative route, we find that average cost pricing for the metro reduces road congestion. Consistent with other coordination games, we also find that coordination problem is more severe with a larger commuter population size. In all our treatments, aggregate route choices are well accounted by the Nash predictions, but not by efficiency standards. Thus, our experiment reinforces the point that any policy initiative need to account for induced change in behavior, and demonstrates both strength and weakness of the equilibrium theory. We find that on one hand, the adjustments in traffic flows respond predictably to the exogenous changes to the network design; but on the other hand, there is an off-setting, persistent variability in traffic flows. Given some persistent individual randomness in behavior, we estimate 
statistical quantal response equilibrium and find that the QRE model explains the data patterns quite well.

To end, it seems clear that a better empirical understanding of commuters' route choice behavior would aid greatly in addressing whether the standard equilibrium assumption is satisfied in real networks and, if it is not, how the resulting problems of forecasting route choices and link volumes might be resolved. While laboratory experiments cannot offer iron-clad solutions to policymakers, they do elucidate the different effects - anticipated and unanticipated - of alternative government policies. They offer a quick, cost-effective way to identify market and policy flaws before ideas and theories become major public policy initiatives. In terms of transport policies, our results overwhelmingly indicate that, ceteris paribus, improving road capacity will not ease traffic congestion. We also find support for average cost pricing structure for the mass transit alternative. 

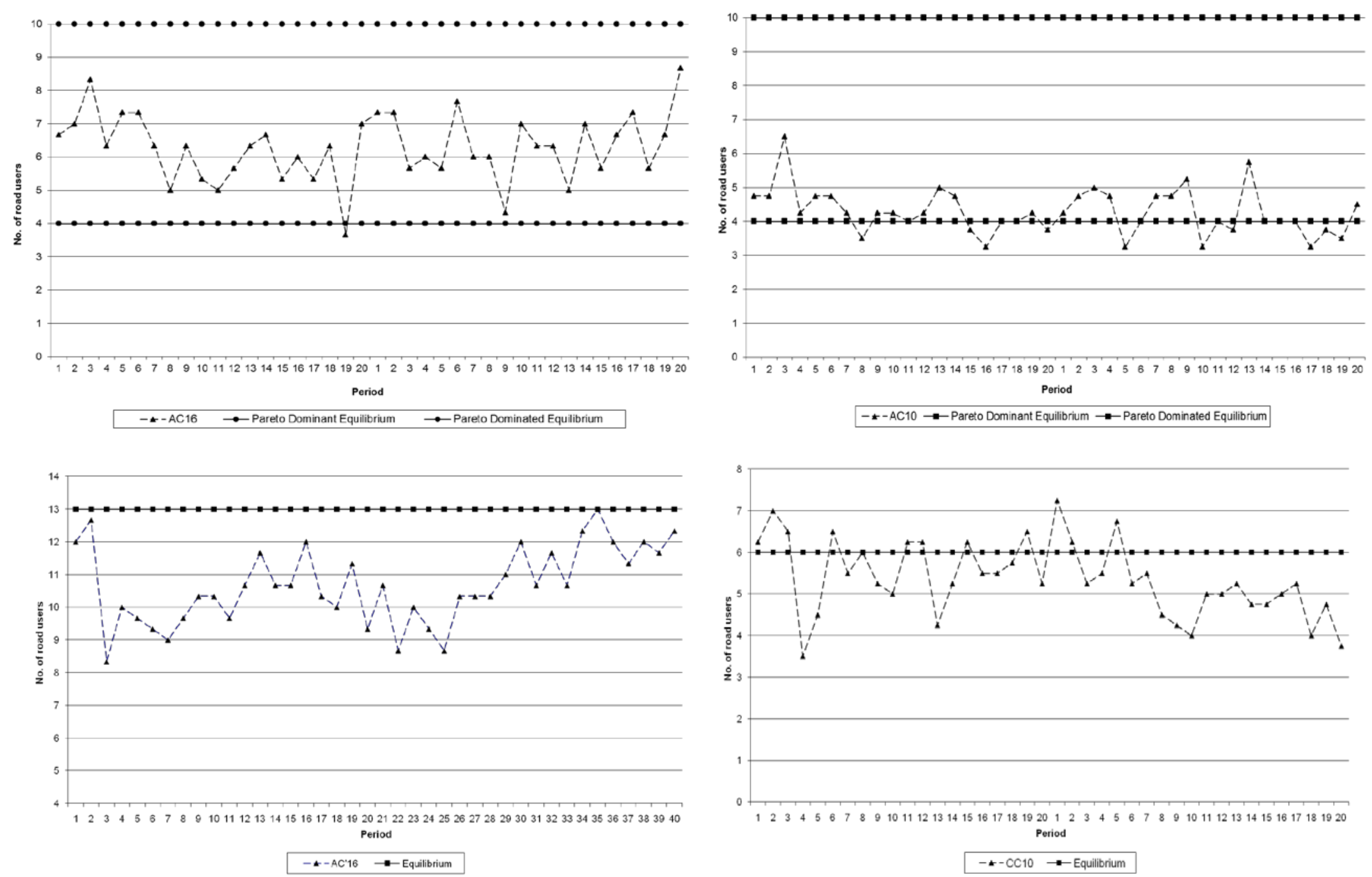

Figure 3. Average number of road users 


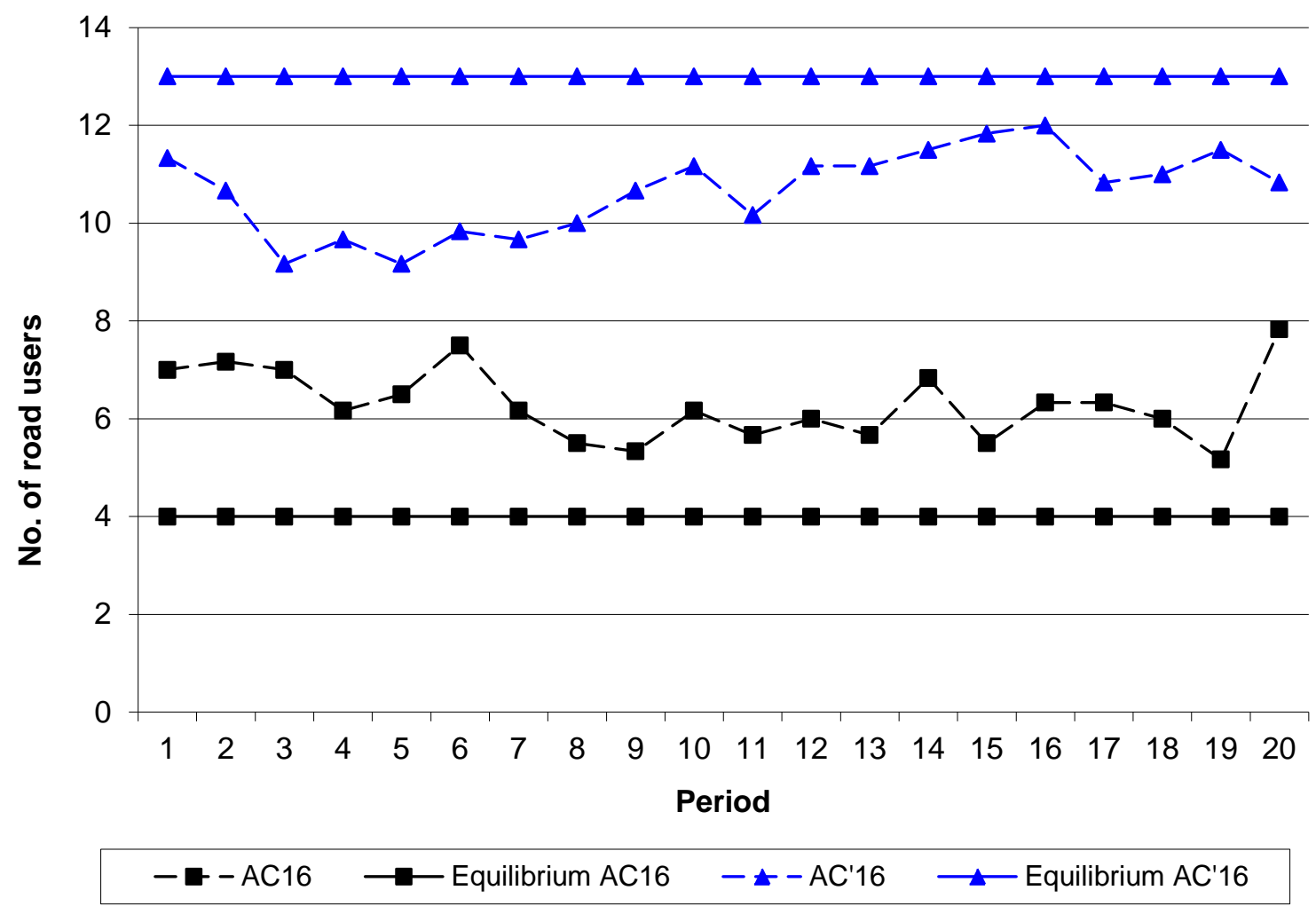

Figure 4. DT comparison 


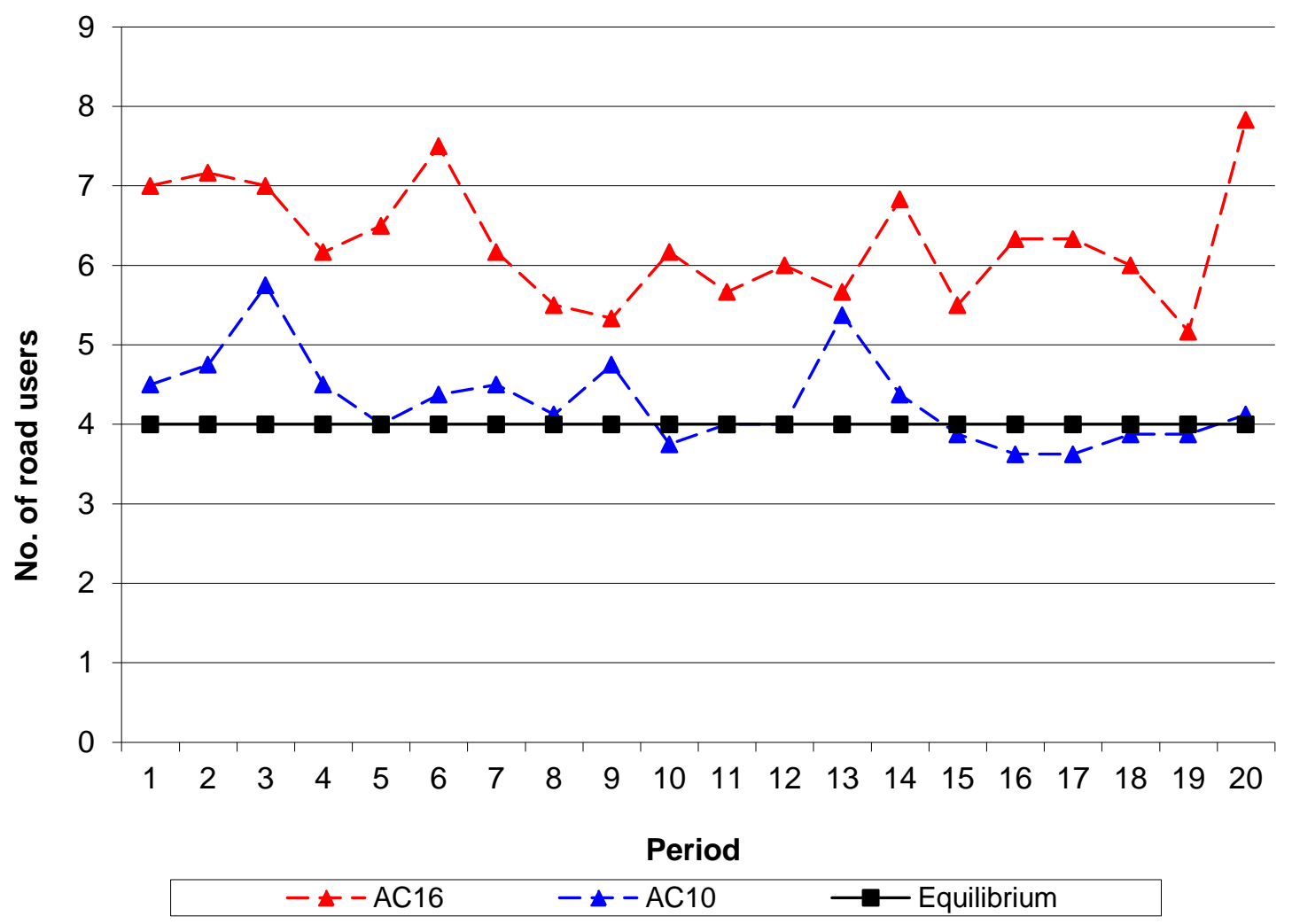

Figure 5. Size comparison 


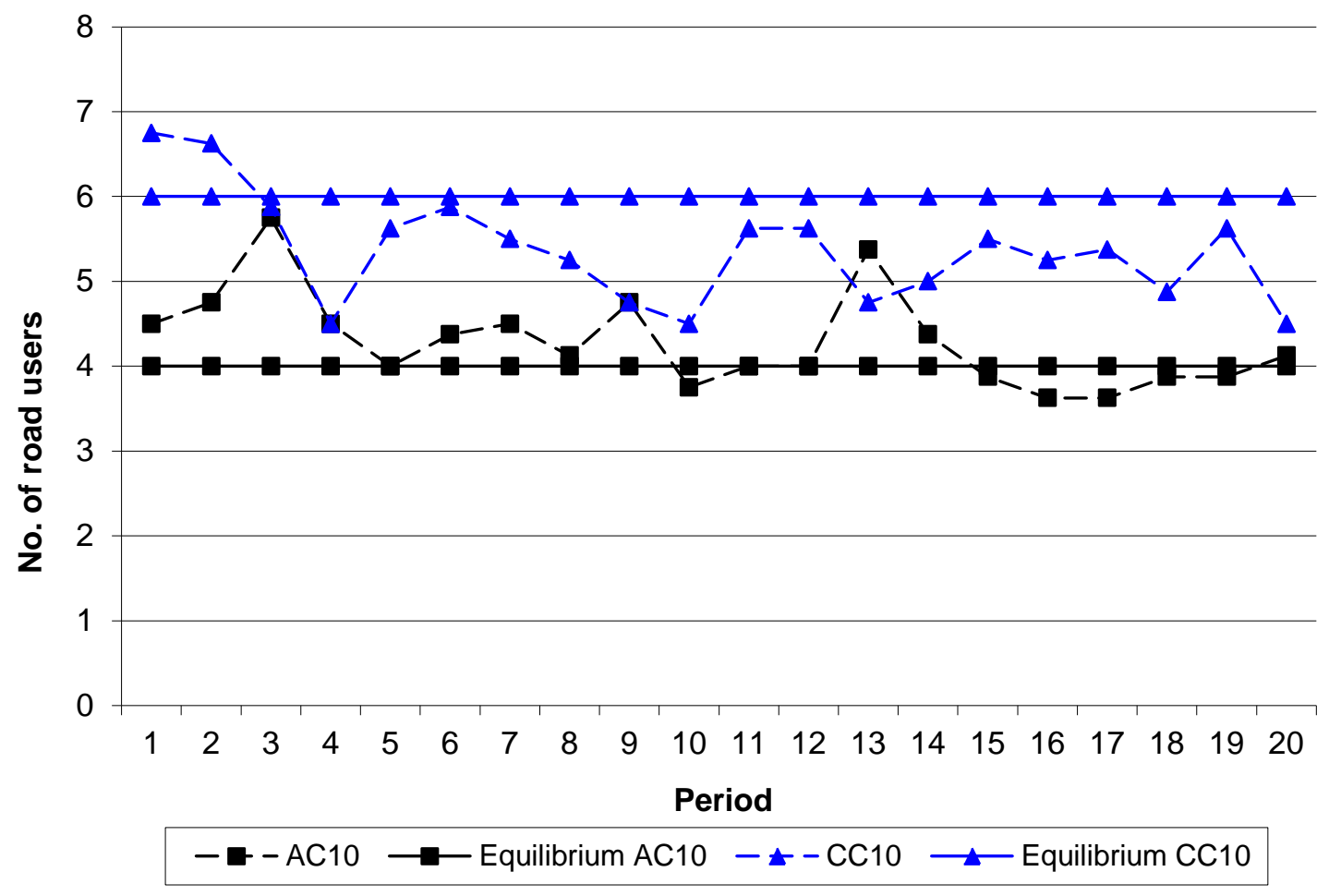

Figure 6. Price comparison 


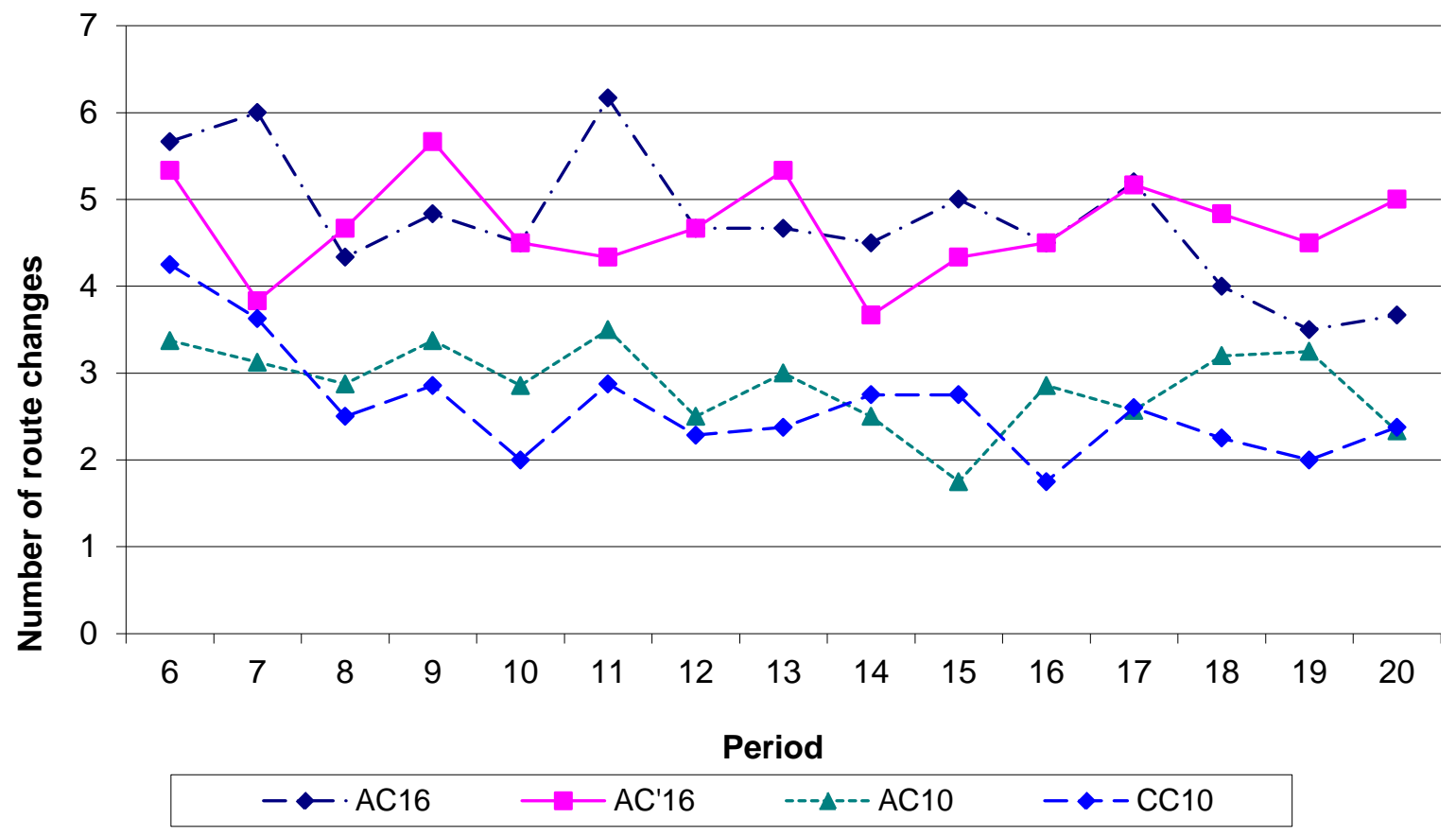

Figure 7. Average number of route changes 


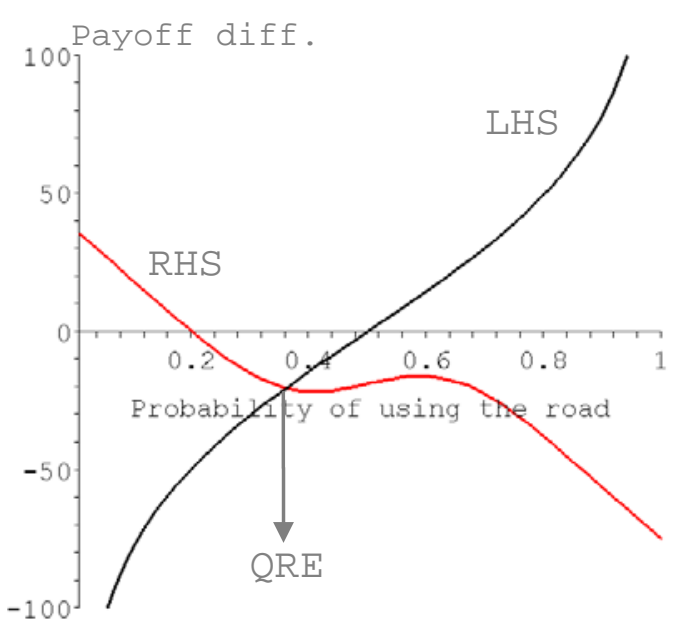

AC16

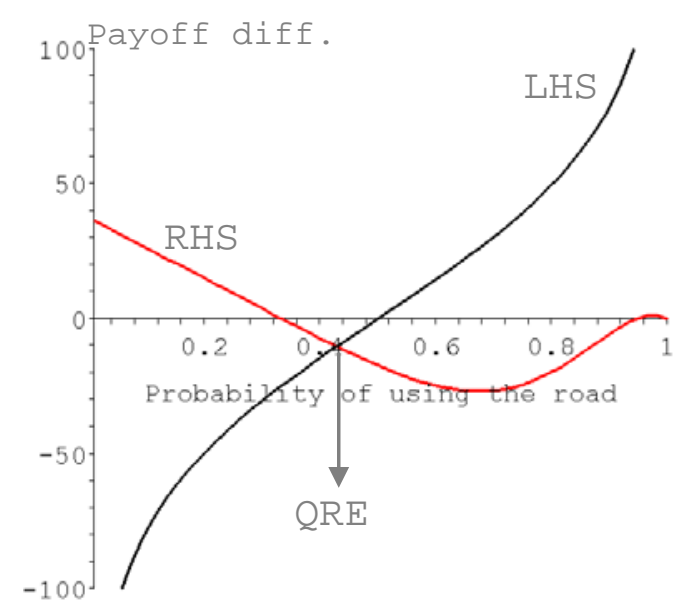

AC10

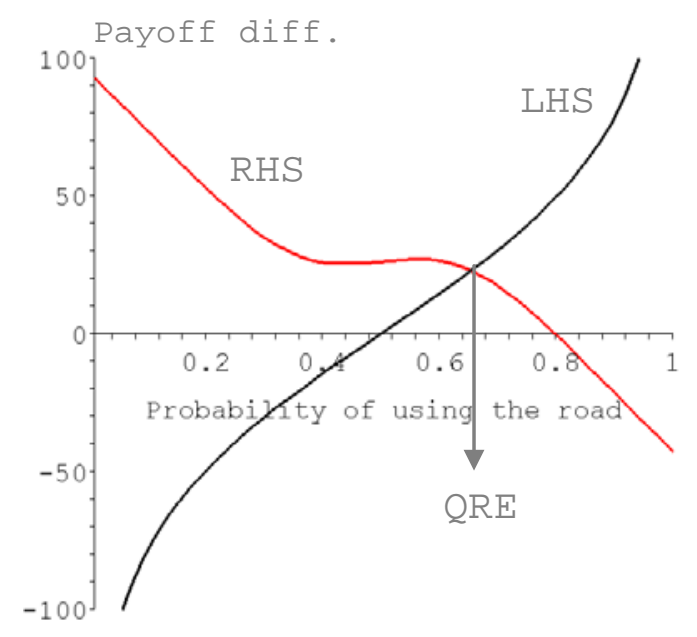

AC'16

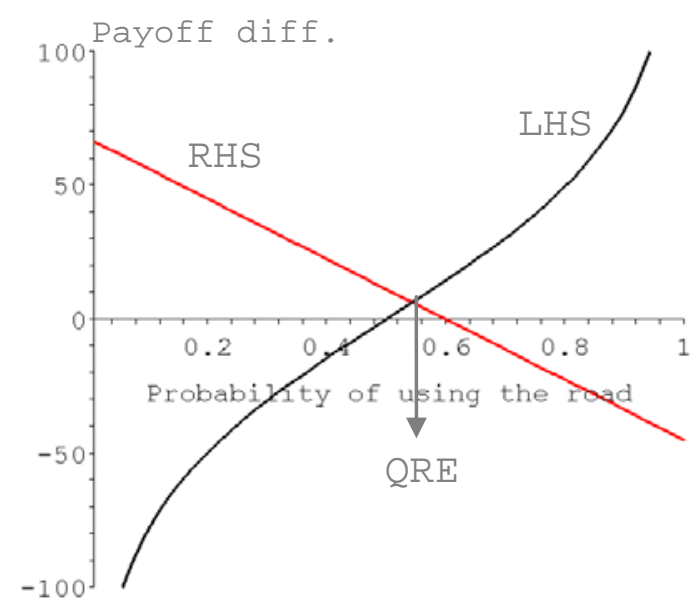

Figure 8. Illustration of the logit QRE for the four different treatments. All figures are drawn using $\boldsymbol{\mu}=\mathbf{0 . 0 2 8}$. 


\section{Appendix}

\section{Instructions}

\section{General Instructions}

This is an experiment in the economics of strategic decision-making. Various research agencies have provided funds for the conduct of this research. The instructions are simple and if you follow them carefully and make good decisions you may earn a considerable amount of money that will be paid to you in cash at the end of the experiment. It is in your best interest to fully understand the instructions, so please feel free to ask any questions at any time. It is important that you do not talk or discuss your information with other participants in the room until the session is over.

This experiment consists of 2 sections. In each section there will be 20 periods. Therefore, you will make a total of 40 decisions. All transactions will be in experimental dollars. These experimental dollars will be converted to real US dollars at the end of the experiment at the rate of 250 experimental dollars $=\$ 1$. Notice that the more experimental dollars you earn, the more US dollars you earn. What you earn depends partly on your decisions and partly on the decisions of other 15 participants in this experiment. Also, for agreeing to participate, you will be given \$3 US as show-up fee. Any additional earnings you make in this experiment will be added to this show-up fee.

\section{Specific Instructions for Section 1}

You must travel to some Destination D. When you reach D, you will earn 275 experimental dollars. To reach D, you must choose between two options: Route $\mathbf{A}$ and Route B. You will pay a cost for traveling along each route. See the cost schedule accompanying these instructions.

Travel cost on Route A depends on the number of players that also choose Route A. Note that if you choose Route A, your payoff decreases as the number of other players choosing Route A increases, and vice versa.

Travel cost on Route B is equal to 150 or 225 experimental dollars, depending again on how many other players chose Route B.

\section{Your payoff from reaching destination $D=275-$ Your Travel Cost}




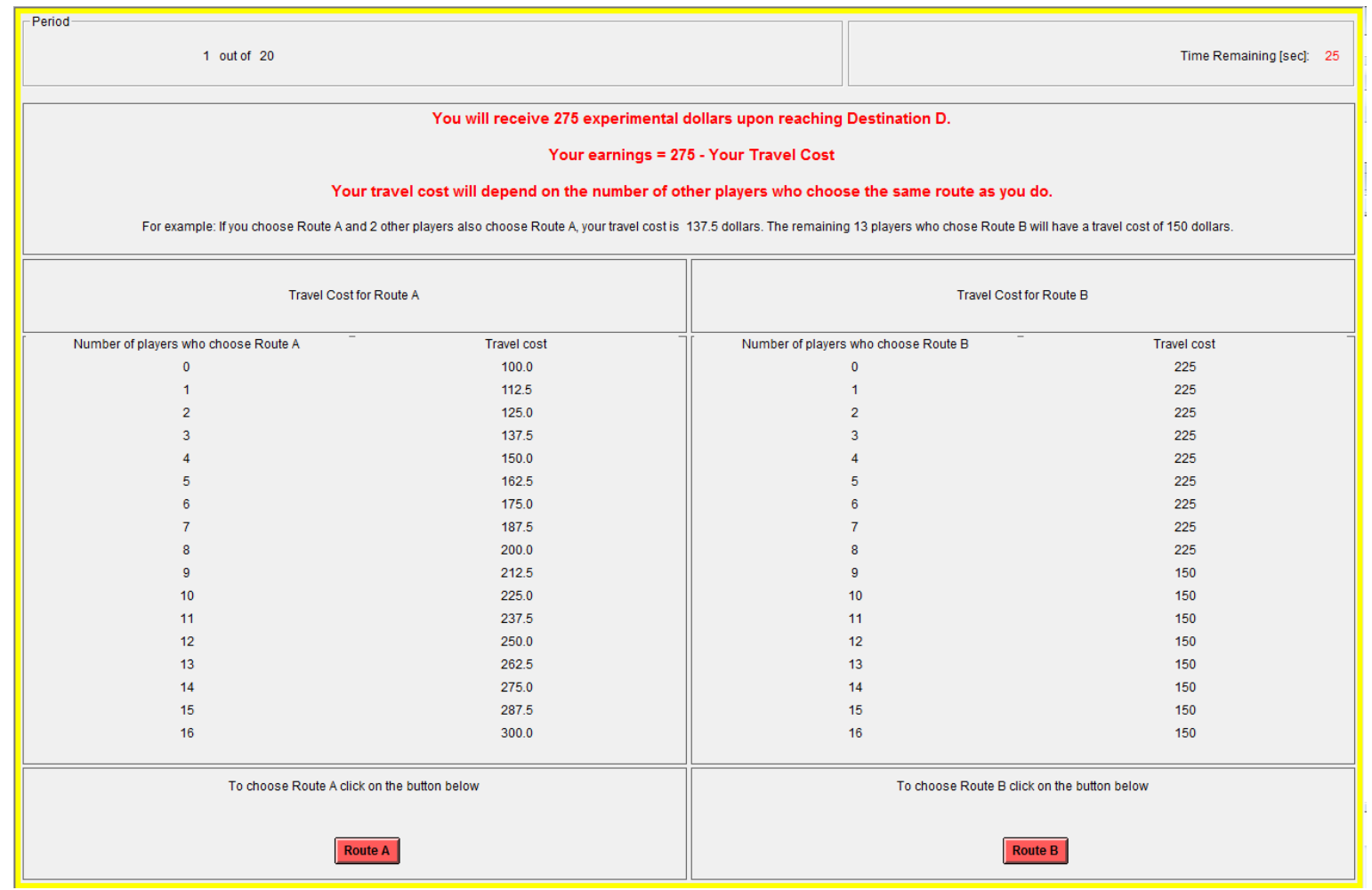

Figure 1. Decision Screen

Example 1: Suppose in a particular period you choose Route A and 1 other player also chooses Route A. This means that a total of 2 players choose Route A. Then the travel cost for each player from Route A is 125 and you will each receive 150 (= $275-125$ ) experimental dollars. The remaining 14 players who chose Route B pay a travel cost of 150 and receive a payoff of 125 (=275 -150) experimental dollars.

Example 2: Suppose in a particular period you choose Route A and there are 11 other players who also choose Route A. This means that a total of 12 players choose Route A. Then the travel cost for each player from Route A is 250 and you will each receive 25 (= 275 - 250) experimental dollars. The remaining 4 players who chose Route B pay a travel cost of 225 and receive a payoff of $50(=275-225)$ experimental dollars.

You must click on either Route A button or Route B button to submit your travel decision. You cannot communicate or coordinate your choice with other players in any manner. The computer will wait until all players have made their decisions before displaying your period payoff in the next screen. See Figure 2 below. 


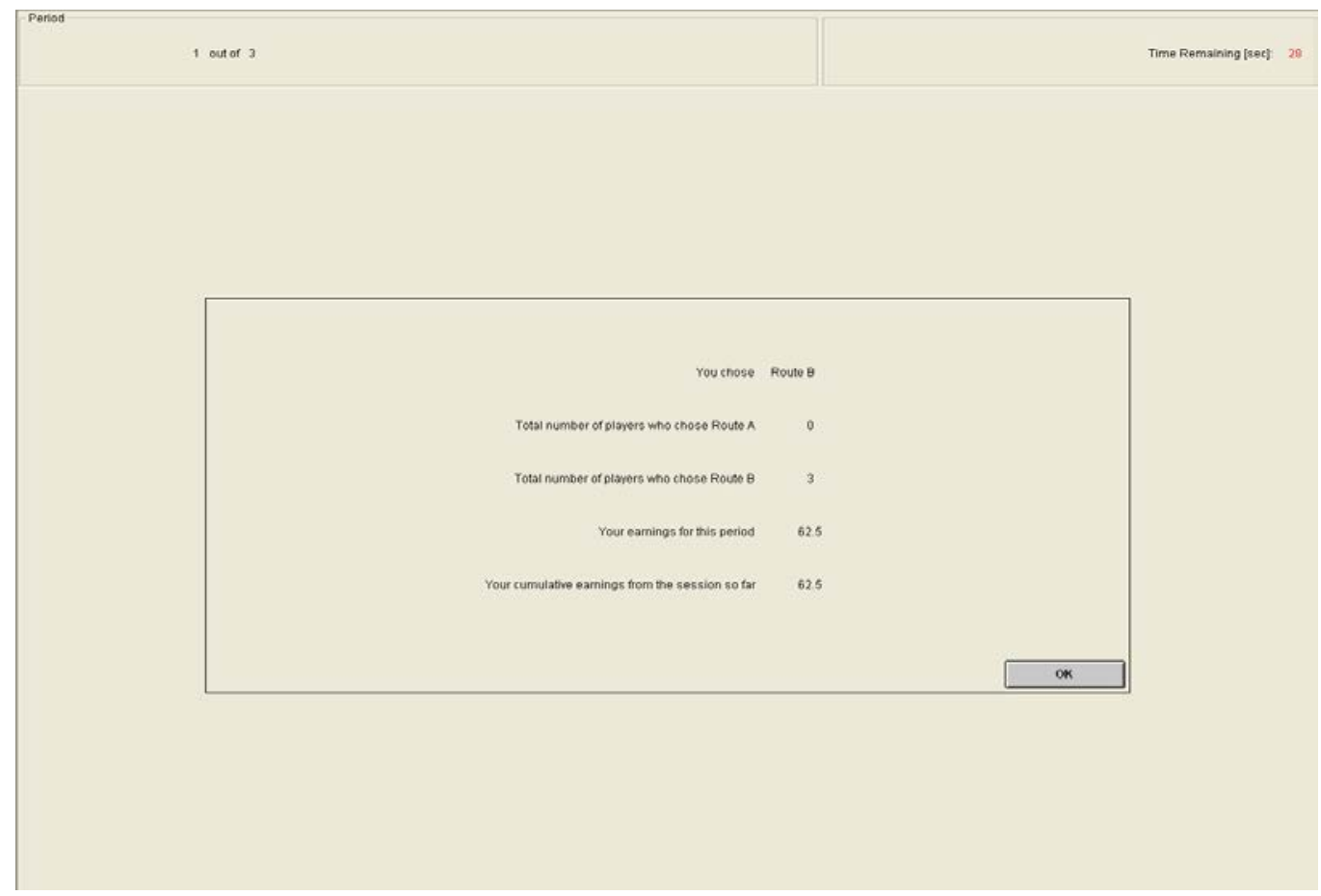

Figure 2. Outcome Screen

Once the outcome screen is displayed, you should record in your Personal Record Sheet the decision information: your choice, number of players who chose Route A and Route $B$, your earnings from this period and from the session so far. Then click on the button on the lower right of your screen to begin the next decision period. 


\section{Cost Schedule for Section 1}

\begin{tabular}{|c|c|c|c|}
\hline $\begin{array}{c}\text { Number of players } \\
\text { who chose Route A }\end{array}$ & $\begin{array}{c}\text { Travel Cost for } \\
\text { Route A }\end{array}$ & $\begin{array}{c}\text { Number of players } \\
\text { who chose Route B }\end{array}$ & $\begin{array}{c}\text { Travel Cost } \\
\text { for Route B }\end{array}$ \\
\hline \hline 0 & 100 & 0 & 225 \\
\hline 1 & 112.5 & 1 & 225 \\
\hline 2 & 125 & 2 & 225 \\
\hline 3 & 137.5 & 3 & 225 \\
\hline 4 & 150 & 4 & 225 \\
\hline 5 & 162.5 & 5 & 225 \\
\hline 6 & 165 & 6 & 225 \\
\hline 7 & 187.5 & 7 & 225 \\
\hline 8 & 200 & 8 & 225 \\
\hline 9 & 212.5 & 9 & 150 \\
\hline 10 & 225 & 10 & 150 \\
\hline 11 & 237.5 & 11 & 150 \\
\hline 12 & 250 & 12 & 150 \\
\hline 13 & 262.5 & 13 & 150 \\
\hline 14 & 275 & 14 & 150 \\
\hline 15 & 287.5 & 15 & 150 \\
\hline 16 & 300 & 16 & 150 \\
\hline
\end{tabular}




\section{References}

Anderson, L., C. Holt, and D. Reiley, (2008). Congestion Pricing and Welfare: An Entry Experiment.", in Experimental Methods, Environmental Economics, Todd L. Cherry, Stephan Kroll, and Jason Shogren, eds., Routledge, UK.

Arnott, R. and K. Small, (1994). The Economics of Traffic Congestion. American Scientist, 82, 446-455.

Camerer, C., (2003). Behavioral Game Theory. Princeton University Press: Princeton, New Jersey.

Chmura, T. and T. Pitz, (2004a). An Extended Reinforcement Algorithm for Estimation of Human Behavior in Congestion Games, Bonn Econ Discussion Paper 24/2004, Bonn Graduate School of Economics.

Chmura, T. and T. Pitz, (2004b). Minority Game - Experiments and Simulations of Traffic Scenarios, Bonn Econ Discussion Paper 23/2004, Bonn Graduate School of Economics.

Denant-Boèmont L. and S. Hammiche, (2010). Downs Thomson Paradox in Cities and Endogenous Choice of Transit Capacity: An Experimental Study, Journal of Intelligent Transport Systems: Technology, Planning, and Operations, 14 (3), 140-153

Downs, A., (1962). The Law of Peak-hour Expressway Congestion, Traffic Quarterly, 16, 393-409.

Fischbacher, U., (2007). z-Tree: Zurich Toolbox for Ready-Made Economic Experiments, Experimental Economics, 10, 171-178.

Gabuthy, Y., M. Neveu, and L. Denant- Boèmont, (2006). Structural Model of PeakPeriod Congestion: An Experimental Study, Review of Network Economics, 5, 273-298.

Goeree, J. and C. Holt, (2005a). An Experimental Study of Costly Coordination. Games and Economic Behavior, 51, 349-364.

Goeree, J. and C. Holt, (2005b). An Explanation of Anomalous Behavior in Models on Political Participation, American Political Science Review, 99(2), 201-213.

Helbing, D., (2004). Dynamic Decision Behavior and Optimal Guidance through Information Services: Models and Experiments. In: M. Schreckenberg and R. Selten (eds.), Human Behavior and Traffic Networks, Springer: Berlin, 47-95.

Horowitz, J.L., (1984). The Stability of Stochastic Equilibrium in a Two-Link Transportation Network. Transportation Research B, 18, 13-28. 
Knez, M., and C. Camerer, (1994). Creating Expectational Assets in the Laboratory: Coordination in 'Weakest-Link’ Games. Strategic Management Journal. 15, 101-119.

McKelvey, R.D., and T.R. Palfrey (1995). “Quantal Response Equilibrium for NormalForm Games,” Games and Economic Behavior, 10, 6-38.

Mogridge, M.J.H., (1990). Travel in towns: jam yesterday, jam today and jam tomorrow? Macmillan Press, London.

Morgan, J., H. Orzen, and M. Sefton, (2009). Network Architecture and Traffic flows: Experiments on the Pigou-Knights-Downs and Braess Paradoxes. Games and Economic Behavior, 66, 348-372.

Putnam, R. D., (2000). Bowling Alone: Collapse and Revival of American Community. New York: Simon \& Schuster.

Rapoport, A., D. Seale, I. Erev and J. Sundali, (1998). Equilibrium Play in Large Group Market Entry Games, Management Science, 44, 119-141.

Rapoport, A., W. Stein, J. Parco and D. Seale, (2004). Equilibrium Play in Single-Server Queues With Endogenously Determined Arrival Times, Journal of Economic Behavior \& Organization, 55, 67-91.

Rapoport, A., V. Mak and R. Zwick, (2006). Navigating Congested Networks with Variable Demand: Experimental Evidence. Journal of Economic Psychology, 27, 648666.

Rapoport, A., T. Kugler, S. Dugar and E. Gisches, (2008). Braess Paradox in the Laboratory: An Experimental Study of Route Choice in Traffic Networks with Asymmetric Costs. In: T. Kugler, J.C. Smith, T. Connolly and Y.J. Son (eds.), Decision Modeling and Behavior in Uncertain and Complex Environments. Springer: Berlin.

Rapoport, A., T. Kugler, S. Dugar and E. Gisches, (2009). Choice of Routes in Congested Traffic Networks: Experimental Tests of the Braess Paradox. Games and Economic Behavior, 65, 538-571.

Schneider, K. and J. Weimann, (2004). Against all Odds: Nash Equilibria in a Road Pricing Experiment. In: M. Schreckenberg and R. Selten (eds.), Human Behaviour and Traffic Networks, Springer: Berlin, 133-153.

Selten, R., T. Chmura, T. Pitz, S. Kube and M. Schreckenberg, (2007). Commuters Route Choice Behavior. Games and Economic Behavior, 58, 394-406.

Sundali, J, A. Rapoport, A. and D. Seale, (1995). Coordination in Market Entry Games 
with Symmetric Players, Organizational Behavior and Human Decision Processes, 64, 203-218.

Thomson, A., (1977). Great Cities and their Traffic, Gollancz, London (Published in Peregrine Books, 1978)

Van Huyck, J., R. Battalio, F. Rankin, (2007). Evidence on Learning in Coordination Games. Experimental Economics, 10, 205- 220.

Ziegelmeyer, A., F. Koessler, K. Boun My and L. Denant-Boèmont, (2008). Road Traffic Congestion and Public Information: An Experimental Investigation, Journal of Transport Economics and Policy, 42, 43- 82. 